\title{
DISTRIBUIÇÃO DO IGF-I E DO SEU RECEPTOR NA CARTILAGEM DO PROCESSO CONDILAR DA MANDÍBULA E NA SINCONDROSE BASIESFENOIDAL DE RATOS WISTAR SUBNUTRIDOS
}

Tese apresentada ao Programa de Pós-Graduação em Ciências Morfofuncionais do Instituto de Ciências Biomédicas da Universidade de São Paulo, para obtenção do Título de Doutor em Ciências.

São Paulo

2013 
DISTRIBUIÇÃO DO IGF-I E DO SEU RECEPTOR NA CARTILAGEM DO PROCESSO CONDILAR DA MANDÍBULA E NA SINCONDROSE BASIESFENOIDAL DE RATOS WISTAR SUBNUTRIDOS

Tese apresentada ao Programa de Pós-Graduação em Ciências Morfofuncionais do Instituto de Ciências Biomédicas da Universidade de São Paulo, para obtenção do Título de Doutor em Ciências.

Área de concentração: Ciências Morfofuncionais.

Orientador: Prof. Dr. Edson Aparecido Liberti

Versão original

São Paulo 
DADOS DE CATALOGAÇÃO NA PUBLICAÇÃO (CIP)

Serviço de Biblioteca e Informação Biomédica do

Instituto de Ciências Biomédicas da Universidade de São Paulo

(C) reprodução total

Oliveira, Bruna Cecilia Caixeta de.

Distribuição do IGF-I e dos seus receptores na cartilagem do processo condilar da mandíbula e na sicondrose basiesfenoidal de ratos Wistar subnutridos / Bruna Cecilia Caixeta de Oliveira. -- São Paulo, 2013.

Orientador: Prof. Dr. Edson Aparecido Liberti.

Tese (Doutorado) - Universidade de São Paulo. Instituto de Ciências Biomédicas. Departamento de Anatomia. Área de concentração:

Ciências Morfofuncionais. Linha de pesquisa: Crescimento craniofacial e subnutrição.

Versão do título para o inglês: Distribuition of IGF-I and its receptor in the cartilage of the mandibular condyle process and basiesphenoidal synchondrosis of the undernourished Wistar rats.

1. Côndilo mandibular 2. Mandíbula 3. Crânio 4. Desnutrição 5. Fatores de crescimento 6. Cartilagem I. Liberti, Prof. Dr. Edson Aparecido II. Universidade de São Paulo. Instituto de Ciências Biomédicas. Programa de Pós-Graduação em Ciências Morfofuncionais III. Título. 


\author{
UNIVERSIDADE DE SÃO PAULO \\ INSTITUTO DE CIÊNCIAS BIOMÉDICAS
}

$\begin{array}{ll}\text { Candidato(a): } & \text { Bruna Cecilia Caixeta de Oliveira. } \\ \text { Título da Tese: } & \text { Distribuição do IGF-I e dos seus receptores na cartilagem do } \\ & \begin{array}{l}\text { processo condilar da mandibula e na sicondrose } \\ \text { basiesfenoidal de ratos Wistar subnutridos. }\end{array}\end{array}$

Orientador(a): Prof. Dr. Edson Aparecido Liberti.

A Comissão Julgadora dos trabalhos de Defesa da Tese de Doutorado, em sessão pública realizada a .................., considerou

\title{
( ) Aprovado(a) ( ) Reprovado(a)
}

Examinador(a): $\quad$ Assinatura:

Nome:

Instituição:

Examinador(a): $\quad$ Assinatura:

Nome:

Instituição:

Examinador(a): $\quad$ Assinatura:

Nome:

Instituição:

Examinador(a): $\quad$ Assinatura:

Nome:

Instituição:

Presidente: Assinatura:

Nome:

Instituição: 


\section{Certificado}

Certificamos que o protocolo registrado sob $n^{\circ} 075$ nas fls. 33 do livro 2 para uso de animais em experimentaçāo, sob a responsabilidade de Silvia de Campos Boldrini, Coordenador(a) da Linha de Pesquisa "Efeito da desnutrição protéica pré e pós-natal e da renutrição pós-natal sobre o crescimento craniofacial de ratos wistar nas fases puberal e adulta" do qual participou(aram) o(s) alunos Bruna Cecilia Caixeta de Oliveira, Marcelo Arthur Cavalli, Marcio Cristófaro, Flávia de Oliveira, Mateus Elias Pacheco e os pesquisadores Patricia Castelucci, Edson Aparecido Liberti, está de acordo com os Principios Éticos de Experimentação Animal adotado pelo Colégio Brasileiro de Experimentaçāo Animal (COBEA) e foi aprovado peía COMISSĀO DE ÉTICA EM EXPERIMENTAÇĀO ANIMAL (CEEA) em 22.06.2006.

Säo Paulo, 23 de junho de 2006.

Profa. Dra. Marilia C.L.Seelaender Coordenadora -CEEA - ICB/USP

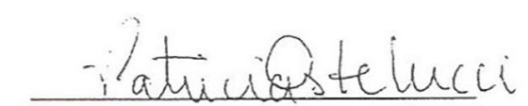

Profa. Dra. Patricia Castelucci Secretária Suplente CEEA - ICB/USP 


\section{DEDICATÓRIA À SILVIA DE CAMPOS BOLDRINI}

A Ela...

É a ela que dedico essa tese.

Dedico e a agradeço pelo carinho, confiança, ensinamentos e pela amizade. Ela foi a minha inspiração e me fez enxergar na "fria" Anatomia o mais caloroso dos caminhos para uma carreira baseada no cuidado com os iguais, pois mesmo com a sua breve participação em minha vida, seu caráter e sua competência me mostrou o verdadeiro sentido da Odontologia e da Anatomia Humana.

Queria mais, desejei e chorei por muito mais.

Mas agradeço a Deus pela oportunidade de tê-la conhecido e ter convivido anos com a nossa Silvia, ela nos encantou e nos contagiou com a sua integridade e sua paixão pela vida.

Silvia de Campos Boldrini (in memorian) você segurou a minha mão, mostrou-me o caminho e partiu. Serei eternamente grata pela sua existência em minha vida. 


\section{AGRADECIMENTOS ESPECIAIS}

À Deus e à minha família.

A minha valente mãe, Angela, pelo amor e pelos esforços na minha criação, juntamente com os meus avós, Dolores e Zé Firmino, que na vossa humildade e sabedoria sempre me ofereceram seus maiores tesouros: amor, dedicação e carinho.

Ao querido Ricardo, que na figura de pai me transmitiu o seu amor e proporcionou condições para a minha criação e formação.

A minha tímida irmã Sabrina e a minha pequenina Catharina pelas imprescindíveis existências em minha vida.

As minhas admiráveis tias Sandra e Márcia, por estarem sempre ao meu lado, oferecendo-me o colo de uma mãe e o ombro de uma amiga.

Ao querido Roberto, por adentrar se em minha vida e despertar meus sentimentos adormecidos. 


\section{AGRADECIMENTOS}

Ao Prof. Dr. Edson Aparecido Liberti, que me acolheu desde o primeiro dia de aula nos "barracões da Anatomia", vi a paixão em seu olhar e no seu entusiasmo, e foram eles que me incentivaram a seguir por essa trilha com tanto carinho, dedicação e humildade. Obrigada por participar da minha vida e me orientar na conclusão deste trabalho.

Ao querido Pedro Boldrini, que conheci pequenino e que agora se transforma num corajoso rapaz.

Aos queridos Ricardos, Bandeira e Eustáquio, que estiveram comigo durante as principais fases dessa jornada. Amparando, acolhendo e ajudando-me como verdadeiros companheiros da vida.

Aos colegas Marcelo Cavalli e Márcio Cristófaro, que trabalharam com dedicação para a execução dos nossos trabalhos.

Aos companheiros das antigas, Dorival Terra Martini, Josemberg Baptista, Thiago Habacuque, William Mayer, Mateus Pacheco, Cibele Maciel de Miranda, Thelma Parada, Lynda Tamayo, Karina do Valle, Ricardo Fontes, Eduardo Beber, tivemos a oportunidade de rir e chorar juntos.

Ao casal Regina Bolina-Matos e Paulo Henrique Matos que com o jeitinho mineiro de ser, promoveram um excelente convívio no laboratório, trazendo ainda a Cris Bolina para aumentar ainda mais o time do LAFACC.

A sorridente Valquiria Mariotti que me ensinou o verdadeiro significado da palavra FÉ.

A minha querida Flavia de Oliveira, que com sua doçura e competência me ensinou a trabalhar com seriedade.

Às "meninas da Silvia", Aline Gonçalves, Diana Vono e Luciliene Luiz, que trabalharam e concluíram com bravura os trabalhos idealizados pela nossa querida orientadora.

Aos jovens e novos alunos de iniciação científica e pós-graduação que trouxeram uma nova energia para o LAFACC. Aproveito o ensejo para lhes desejar muito boa sorte !!!

A querida Martha Maria da Silva Righetti, técnica de histologia, que me acompanhou desde o primeiro corte histológico da iniciação científica até a última lâmina do doutorado e a Sônia Regina Yokomizo, sua colega de trabalho.

Às funcionárias Rosana Duarte Prisco, pelo seu trabalho e atenção em todas as análises estatísticas contidas nesse e em todos os trabalhos por mim desenvolvidos 
nesse Departamento, à Patrícia Rocha pelo seu trabalho desempenhado na secretaria de Pós Graduação do Departamento de Anatomia do ICB.

A funcionária Malu Motta, que com muita competência e coragem se empenhou para a realização dos nossos "Encontros Internacionais de Ensino em Anatomia", além de todo o convívio.

Aos funcionários do Biotério do ICB-III, Fábio França Luiz e ao Renivaldo de Souza pelo diário e árduo trabalho e cuidados com os animais usados nos experimentos.

A todos os funcionários do Departamento de Anatomia do ICB que sempre auxiliaram para o bom funcionamento do Instituto.

E aqueles que me auxiliaram e cujos nomes que, por ventura, tenham sido omitidos, os meus sinceros agradecimentos. 
"Aprendi que vai demorar muito para me transformar na pessoa que quero ser, e devo ter paciência. Mas, aprendi também, que posso ir além dos limites que eu próprio coloquei" Charles Chaplin 


\section{RESUMO}

OLIVEIRA, B. C. C. Distribuição do IGF-I e dos seus receptores na cartilagem do processo condilar da mandíbula e na sincondrose basiesfenoidal de ratos wistar subnutridos. 2013. 73 f. Tese (Doutorado em Ciências Morfofuncionais) - Instituto de Ciências Biomédicas, Universidade de São Paulo, São Paulo, 2013.

A cartilagem do processo condilar (PC), assim como a sincondrose basiesfenoidal (SB) participam ativamente do processo de crescimento e de desenvolvimento do complexo craniofacial. Tais fenômenos são determinados pelo aporte protéico adequado, pela ação de diversos hormônios e fatores de crescimento, dentre eles 0 fator de crescimento semelhante à insulina (IGF-I). Através da avaliação da matriz cartilagínea, das características do arcabouço colágeno e da detecção de IGF-I e do seu receptor (IGF-IR), objetivou-se correlacionar as alterações morfológicas provenientes da subnutrição protéica pré e pós-natal no PC e na SB. Os grupos experimentais foram formados por animais heterogêneos $(n=5)$ de acordo com o teor de caseína contida nas rações oferecidas, protéica $(20 \%)$ ou hipoprotéica $(5 \%)$, formando assim os grupos nutrido $(\mathrm{N})$ e subnutrido $(\mathrm{S})$, respectivamente, processados com 60 dias de vida.

Cortes sagitais do $\mathrm{PC}$ e horizontais da SB foram submetidos às colorações específicas e analisados sob microscopia de luz que permitiram observar o padrão celular, a matriz cartilagínea e o componente colágeno das camadas das cartilagens. A quantificação do IGF-I e do IGF-IR foi realizada em espécimes submetidos à técnica de imunohistoquímica. Para tanto, temos que a subnutrição não foi capaz de alterar as espessuras das camadas do $\mathrm{PC}$ e da SB, porém, o número de condrócitos imunomarcados pelo IGF-I e pelo IGF-IR diminuiu em ambos os tecidos $(N \neq S ; p<0,05)$. Quanto à densidade dos tipos de fibras colágenas e ao arcabouço estrutural, esses demonstraram diferenças entre os grupos do PC, cuja predominância do colágeno do tipo I vista no grupo $\mathrm{N}$, passou a ser do tipo II no grupo $\mathrm{S}$, enquanto que na $\mathrm{SB}$, o colágeno tipo II típico da cartilagem hialina foi destacado em ambos os grupos, $\mathrm{N}$ e $\mathrm{S}$. Com a subnutrição, a densidade das fibras colágenas diminuiu, sendo encontradas principalmente na periferia do tecido. Com relação à matriz extracelular (MEC) do $\mathrm{PC}$, a mesma apresentou-se densa e com coloração homogênea nos animais nutridos, contrastando com o aspecto difuso dos subnutridos. Na SB, tanto no grupo $\mathrm{N}$ quanto no grupo S, a MEC manteve-se com aspecto uniforme na distribuição e na homogeneidade da coloração.

Palavras-chave: Processo Condilar. Sincondrose Basiesfenoidal. Subnutrição protéica. IGF-I. IGF-IR. 


\section{ABSTRACT}

OLIVEIRA, B. C. C. Distribution of IGF-I and its receptor in the cartilage of the mandibular condyle process and basiesphenoidal synchondrosis of the undernourished Wistar rats. 2013. 73 p. Thesis (PhD Morphofunction Sciences) Instituto de Ciências Biomédicas, Universidade de São Paulo, São Paulo, 2013.

The cartilage of the condylar process (CP) and the basiesphenoidal synchondrosis (BS), actively participate in the process of growth and development of the craniofacial complex. Such phenomenon are determined by adequate protein supply and action of various hormones and growth factors, among them the growth factor insulin-like (IGF-I). Through evaluation of the cartilage matrix, characteristics of the collagen framework and detection of IGF-I and its receptor (IGF-IR) aimed to correlate the morphological changes from protein undernourished pre and postnatal in the CP and BS. The experimental groups were formed by heterogeneous animals $(n=5)$, according to the casein contained in the provided feed, proteic $(20 \%)$ ou hypoproteic $(5 \%)$, constituting the nourished $(\mathrm{N})$ and undernourished $(\mathrm{U})$ groups, respectively, rendered with 60 life's day. Sagittais cuts of the CP and horizontais of the BS, underwent specific staining and analyzed under light microscopy that allowed to observe the standard cell, the cartilage matrix and collagen component of cartilage layers. The quantification of the IGF-I and IGF-IR was performed on specimens subjected to immunohistochemical techniques. The undernourished was not able to change the thickness of the layers of the CP and BS, however, the number of chondrocytes immunostained for IGF-I and IGF-IR decreased in both tissues $(\mathrm{N} \neq \mathrm{S} ; \mathrm{p}<0,05)$. As regards density of the types of collagen fibers and the structural framework, these show differences between groups. On the PC, the prevalence of type I collagen found in the group $\mathrm{N}$, became the type II in the group $\mathrm{S}$, while BS, the type II collagen typical of the hyaline cartilage was prominent in both, $\mathrm{N}$ and $S$ groups. With the undernourished, decreased density of the fibers, being found primarily in edge of tissue. With respect to the CP's extracellular matrix it's presented dense and homogeneous staining in nourished animals, contrasting with the diffuse aspect of the undernourished. In the SB, in both groups, remained the ECM aspect uniform distribution and uniformity of coloration.

Keywords: Condyle process. Basiesphenoidal Synchondrosis. Undernourished Proteic. IGF-I. IGR-IR. 


\section{LISTA DE ABREVIATURAS E SIGLAS}

a - Camada articular

ATM - Articulação temporomandibular

ANOVA - Análise de variância

c - Camada condroblática

DP - Desvio padrão

h - Camada hipertrófica

ICB-USP - Instituto de Ciências Biomédicas da Universidade de São Paulo

IGF-I - Insulin-like growth factor -1

IGF-IR - Receptor insulin-like growth fator - 1

p - Camada pré-condroblástica

PC - Processo condilar da mandíbula

r - Camada de repouso

s - Camada seriada

SB - Sincondrose basiesfenoidal

PBS - Solução salina tamponada

N - Grupo experimental nutrido

S - Grupo experimental subnutrido 


\section{LISTA DE ILUSTRAÇÕES}

Figura 1 - Esquema das alças de retroalimentação do eixo GH e IGFs. ..................................................22

Figura 2 - Esquema representativo da formação dos grupos..................................................................29

Figura 3 - Imagens da estante (A) e da gaiola metabólica individualizada (B) ..........................................30

Figura 4 - Etapas para a obtenção do processo condilar da mandíbula (PC) .........................................31

Figura 5 - Etapas para a obtenção da sincondrose basiesfenoidal (SB).................................................32

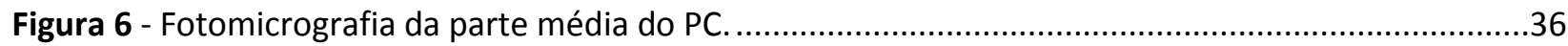

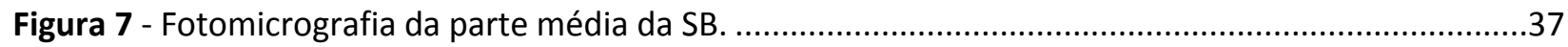

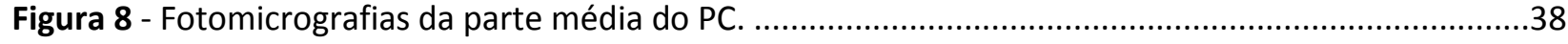

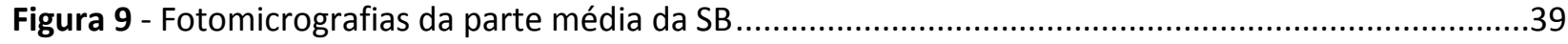

Figura 10 - Representação gráfica das medidas das espessuras obtidas para as camadas do PC.............43

Figura 11 - Representação gráfica das medidas das espessuras obtidas para as camadas da SB..............44

Figura 12 - Micrografias de cortes do PC (A) e da SB (B) imunomarcadas pelo IGF-I e o IGF-IR. ...............45

Figura 13 - Densidade do número de células imunomarcadas no PC....................................................46

Figura 14 - Densidade do número de células imunomarcadas na SB...................................................47

Figura 15 - Fibras colágenas constituintes do PC dos animais nutridos (A) e subnutridos (B)..................48

Figura 16 - Fibras colágenas constituintes da SB dos animais nutridos (A) e subnutridos (B)..................49

Figura 17 - Aspectos da MEC no PC e na SB dos grupos Nutrido $(A, C)$ e Subnutrido (B, D)...................50 


\section{LISTA DE TABELAS}

Tabela 1 - Espessuras das camadas do PC nos grupos Nutrido (N) e Subnutrido (S) . ..............................42

Tabela 2 - Espessuras das camadas da SB nos grupos Nutrido (N) e Subnutrido (S)...............................43

Tabela 3 - Densidade de condrócitos imunorreativos do PC ................................................................45

Tabela 4 - Densidade de condrócitos na parte média da SB. ............................................................46 


\section{SUMARIO}

\section{INTRODUÇÃO E REVISÃO DE LITERATURA}

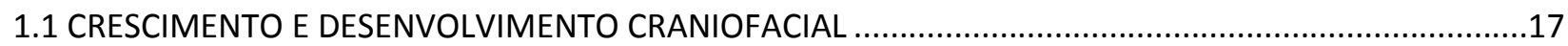

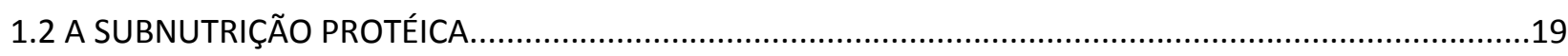

1.3 HORMÔNIO DO CRESCIMENTO E FATORES DE CRESCIMENTO SEMELHANTE À INSULINA....................21

2 PROPOSIÇÃO

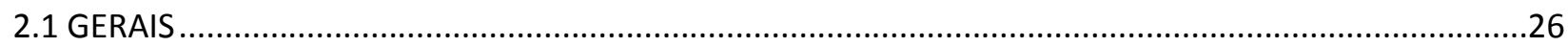

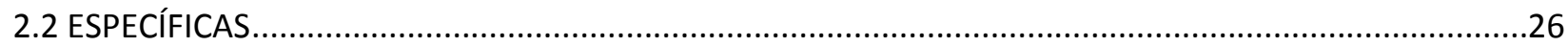

3 MATERIAIS E MÉTODOS

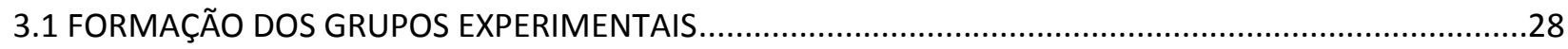

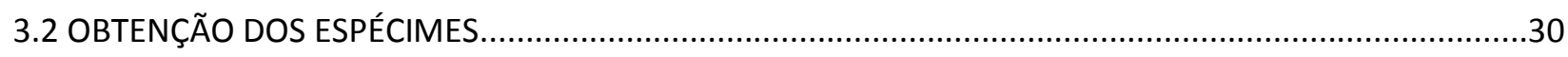

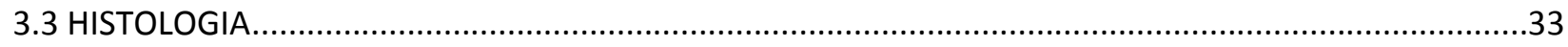

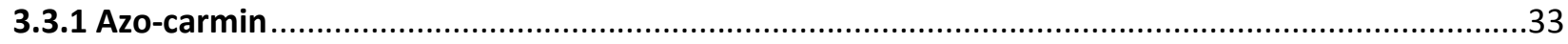

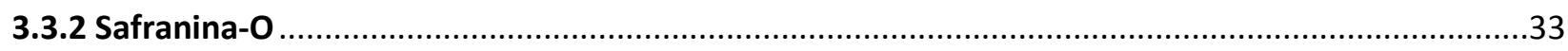

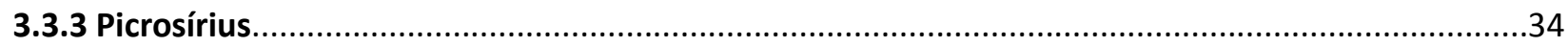

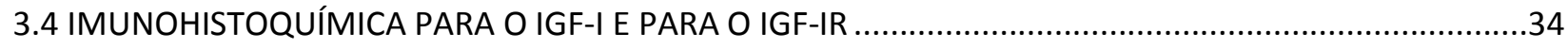

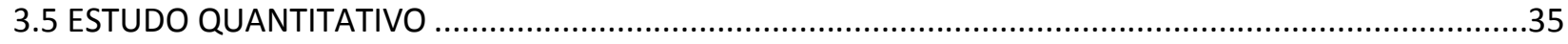

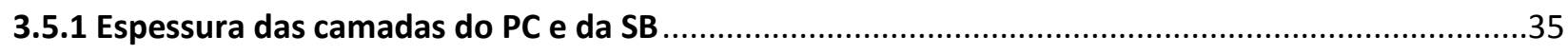

3.5.2 Número de células imunomarcadas nas cartilagens do PC e da SB...........................................37

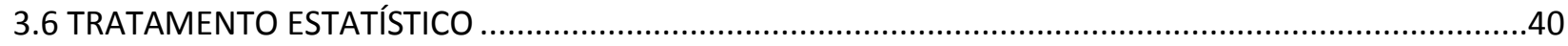

4 RESULTADOS

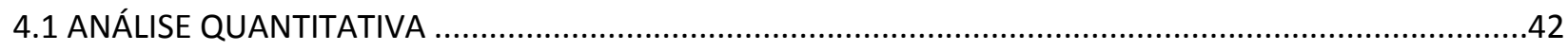

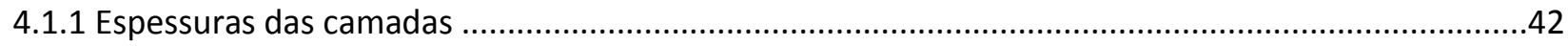

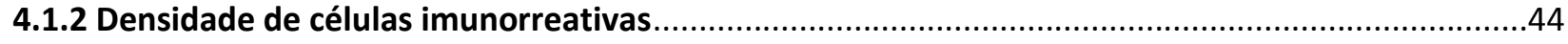

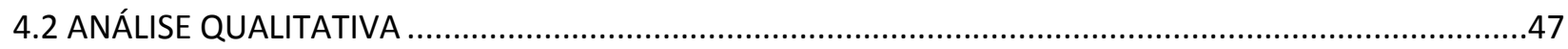

5 DISCUSSÃO

6 CONCLUSÕES

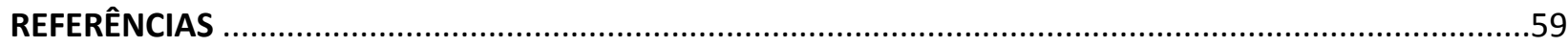


1 INTRODUÇÃO E REVISÃO DE LITERATURA 


\subsection{CRESCIMENTO E DESENVOLVIMENTO CRANIOFACIAL}

O crescimento e o desenvolvimento do complexo craniofacial, representados pelo processo condilar da mandíbula (PC) e pela sincondrose basiesfenoidal (SB), são determinados pelo processo de remodelação e aposição sutural (ENLOW, 1968, 1975; SCHUMACHER, 1999) regidos por fatores intrínsecos (genético e hormonal) e extrínsecos (mecânicos, nutricionais e físicos) (MOYERS, 1991; NEWMAN et al., 1982), dentre os quais o aporte protéico se destaca como um dos mais essenciais (DE OLIVEIRA et al., 2010).

Quando observados de acordo com a sua origem, a SB deriva das cartilagens primárias que, na embriogênese, ocorrem a partir de um condroesqueleto com ossificação do tipo endocondral, e o PC, das cartilagens secundárias, que se diferenciam independentemente do condroesqueleto embrionário e sofrem ossificação intramembranosa.

Ontogeneticamente, a mandíbula deriva da justaposição de cartilagem primária e tecido fibroso que surge das células da crista neural que migram para a região mandibular (HALL, 1994). Durante a embriogênese, a cartilagem primária (ou de Merckel) emerge do condroesqueleto, porém o PC, diferentemente do ramo e corpo da mandíbula, deriva de uma cartilagem secundária independente do condroesqueleto, onde remanescentes do tecido fibrocelular recobrem completamente a cabeça da mandíbula, formando a superfície articular do mesmo (TEN CATE, 1998).

O PC é uma das regiões atuantes na determinação do comprimento e da altura da mandíbula (FUENTES et al., 2002), particularmente a sua cartilagem articular que segundo McNeill (1997), é um importante sítio de crescimento responsável pelo alongamento ântero-posterior de cada hemi-mandíbula. Como demonstrado em estudos, tanto em humanos quanto em animais, a morfologia dos constituintes do PC é constantemente alterada durante todo o período de crescimento normal, principalmente por sua localização e participação em toda a dinâmica da fonação e da mastigação (CARLSON et al., 1978; COPRAY; LIEM, 1989; FURSTMAN, 1966; KANTOMAA et al., 1992; LUDER, 1983; THILANDER et al., 1976; VINKKA, 1982; WRIGHT), assim como 
o tipo de dieta (KILIARIDIS et al., 1999;VAN ERUM et al., 1997; ZHOU et al., 2005) e a predisposição genética (PIRTTINIEMI, et al., 2009).

Localizada na base do crânio entre os ossos interesfenóide e basioccipital, a SB, semelhante à justaposição de duas lâminas epifisiais, participa ativamente no crescimento tanto do viscero, como do neurocrânio. Caracterizada como uma articulação cartilagínea temporária, a proliferação de suas células é seguida por um processo de degeneração, o que associado ao fato de apresentar dois pólos de crescimento, potencializa o seu alongamento e o consequente afastamento dos ossos por ela articulados. Comparada em função à sincondrose esfeno-occipital do homem, que determina o crescimento ântero-posterior da base craniana, muito embora exista nessa mesma região do crânio do rato a sincondrose interesfenoidal, a SB é a principal responsável pelo alongamento da base do crânio desses animais.

Tanto a cartilagem do PC quanto a da SB exibem camadas histológicas, que consistem de componentes celular e intercelular.

Relativamente ao PC, verifica-se no mesmo uma matriz extracelular composta por proteoglicanas e elementos fibrosos, a maior parte destes representados por fibras colágenas dos tipos I, II e X, que lhe confere resistência às forças tensionais (TERAMOTO et al., 2003). A partir da superfície, O PC apresenta uma camada exclusivamente fibrosa, a camada articular (a), abaixo da qual se encontra a camada pré-condroblástica $(p)$, com células indiferenciadas e potencialmente cartilagíneas. $O$ extrato seguinte, a camada condroblástica (c), é caracterizada por apresentar células ativas responsáveis por secretar a matriz extracelular sendo a última camada denominada de hipertrófica (h), que está justaposta ao osso subcondral em formação (CARLSON et al., 1980; FUENTES et al., 2002). A disposição das camadas na SB é definida, sequencialmente a partir do osso subcondral como camadas hipertrófica $(h)$, seriada (s) e condroblástica (c), encontrando-se na sua parte mais central, a zona de repouso $(r)$, com disposição semelhante à de duas lâminas epifisiais justapostas. 


\subsection{A SUBNUTRIÇÃO PROTÉICA}

A subnutrição, especialmente a protéica, é considerada como o maior fator não genético que afeta a taxa e o tempo de crescimento nos humanos (GOLDEN, 1994; MALCOLM, 1979). Em animais de laboratório, os níveis mínimos de proteínas considerados para que ocorra um aumento no peso corpóreo estão entre 5 e 10\%, e de $25 \%$ para promover um crescimento acelerado (EDOZIEN; SWITZER, 1978).

A subnutrição infantil apresenta-se como um dos principais problemas de saúde pública das sociedades atuais, devido às consequências muitas vezes irreparáveis com relação ao crescimento e ao desenvolvimento do indivíduo. Por serem as crianças mais vulneráveis às deficiências nutricionais, a subnutrição, intimamente correlacionada com a pobreza, é a responsável por cerca de um terço da mortalidade infantil mundial e, ainda, a segunda causa de morte mais frequente em menores de 5 anos nos países em desenvolvimento (MONTE, 2000), quando severa pode agir como uma causa direta ou indireta de morte, pois aumenta drasticamente a letalidade em crianças que sofrem de doenças relativamente comuns na infância, como diarreia e pneumonia. As estimativas atuais sugerem que as crianças gravemente subnutridas têm de 10 a 20 vezes mais risco de morrer do que as bem nutridas. Tendo em conta que cerca de $1-2 \%$ da população de menores de 5 anos nos países em desenvolvimento são afetados pela subnutrição grave, isso pode corresponder a cerca de um milhão de mortes de crianças a cada ano (WHO, 2005).

Dentre as consequências determinadas pela subnutrição, a privação protéica é especialmente relevante para a constituição dos diferentes órgãos, promovendo alterações em diversos tecidos, como o tegumento (LANSDOWN, 1978; NAEYE, 1965), o aparelho locomotor (ADAMS, 1971; SHRADER, ZEMAN, 1969) e a parte central do sistema nervoso (YAMANO et al., 1980).

A disponibilidade de proteína, um fator limitante no crescimento dos mamíferos em geral (MILLER; GERMAN, 1999; REICHLING; GERMAN, 2000), quando restrita na dieta afeta a trajetória do crescimento do esqueleto, cujas diferentes regiões respondem de forma diversa aos períodos em que se instala a subnutrição (BRETON, 1995; COUPÉ, 2009). 
Relativamente ao crescimento craniofacial, é durante o desenvolvimento pósnatal que se denotam as transformações mais importantes desse complexo, como o relativo aumento da região facial e progressiva tendência à ortocefalização (PUCCIARELLI, 1978).

Por apresentar duas regiões distintas, o viscerocrânio e o neurocrânio, o seu desenvolvimento é complexo, uma vez que a primeira, por participar dos processos decorrentes da alimentação e da respiração, está sujeita as ações musculares contínuas (CHEVERUD, 1982; HERRING, 1993), ao passo que a segunda, por alojar o encéfalo, tem o seu crescimento influenciado principalmente pela expansão desse órgão (YOUNG, 1959) e parece ser menos susceptível aos fatores epigenéticos (FIELDS, 1991; PUCCIARELLI, 1980; 1981).

Para Moyers (1991), a subnutrição protéica representa um dos fatores extrínsecos determinantes dentre aqueles que incidem sobre o crescimento craniofacial, assunto este ainda carente de informações específicas disponíveis.

Autores como Nakamoto et al. (1983) relataram que, durante a gestação, a subnutrição protéica afeta de maneira diferente os dois tipos de ossificação que ocorrem no esqueleto dos mamíferos - a endocondral, típica dos ossos longos, e a intramembranosa, que ocorre na maioria dos ossos da cabeça.

Alippi et al. (1984) observaram em mandíbulas de ratos submetidos à subnutrição protéica a partir da época do desmame, alterações nas proporções de suas partes (como o ramo e o corpo), o suficiente para conferir a esse osso, um certo grau de deformação incapaz de retomar um padrão normal de crescimento, devido às alterações permanentes que ocorrem na sua estrutura.

Pucciarelli e Oyhenart (1987) ao avaliarem o crescimento craniofacial de ratos durante o período de amamentação, classificaram as carências nutricionais como um dos fatores não-genéticos capazes de determinar desvios nos padrões normais tanto no crescimento rápido e de curta duração (neurocrânio), como no sustentado e de longa duração (esplancnocrânio), determinantes do processo de ortocefalização.

Reforçando essa teoria, Moyers (1991) mais uma vez descreveu a nutrição como uma variável que atua sobre o crescimento craniofacial, destacando a má nutrição como um fator desorganizador desse crescimento. 


\subsection{HORMÔNIO DO CRESCIMENTO E FATORES DE CRESCIMENTO SEMELHANTE À INSULINA}

Dentre os fatores intrínsecos que regulam o crescimento das cartilagens primárias e secundárias, os fatores de crescimento semelhantes à insulina (IGFs), tumoral (TGF- $\beta 1$ ) e de fibroblasto (FGF-2) são mediadores que se expressam na lâmina epifisial, onde regem a proliferação dos condrócitos (DELATTE et al., 2004), e na cartilagem do PC atuando sobre o crescimento da mandíbula (LIVNE et al., 1997, MOLTENI et al.,1999). Fatores anabólicos e catabólicos controlam a biologia dos condrócitos nos níveis celular e molecular (GOLDRING; GOLDRING, 2004), destacando-se muitas famílias de fatores de crescimento como importantes moduladores da biologia e da degeneração do tecido cartilagíneo (SILVERTHORN et al., 2003).

Entretanto, a síntese de alguns fatores de crescimento (TAJIMA et al., 1998 VISNAPUU et al., 2002) e a expressão de seus receptores são diferentes entre as cartilagens primárias e secundárias (VISNAPUU et al., 2001). A mandíbula tem um crescimento pronunciado durante os períodos pré - púbere e púbere (BJORK; SKILLER, 1976) sincronizados com o crescimento linear em ambos os sexos (BOJRK; HELM, 1967), certificando a presença de influência hormonal. Tem sido também sugerido que os mecanismos de proliferação da cartilagem constituinte do PC, podem ter muito em comum com aqueles que atuam nas suturas cranianas, ou mesmo nas lâminas epifisiais (FUENTES et al., 2002).

Pelo fato dos IGFs serem semelhantes à insulina na ação e regulação do crescimento, os mesmos serão aqui abordados em uma possível interação com o estado nutricional. O IGF-I e IGF-II são os principais representantes da família dos IGFs ou somatomedinas (GUYTON, HALL, 2006). Secretados principalmente pelo fígado, pelo pâncreas (ação endócrina) e localmente em outros tecidos (ação parácrina/autócrina) quando estimulados pelo hormônio de crescimento $(\mathrm{GH})$ (SILVERTHORN, et al., 2003), também participam da retroalimentação do $\mathrm{GH}$ interferindo no eixo hipotálamo-hipófise (CONSTANZO, 2004) (Figura 1). 
Figura 1 - Esquema das alças de retroalimentação do eixo GH e IGFs.

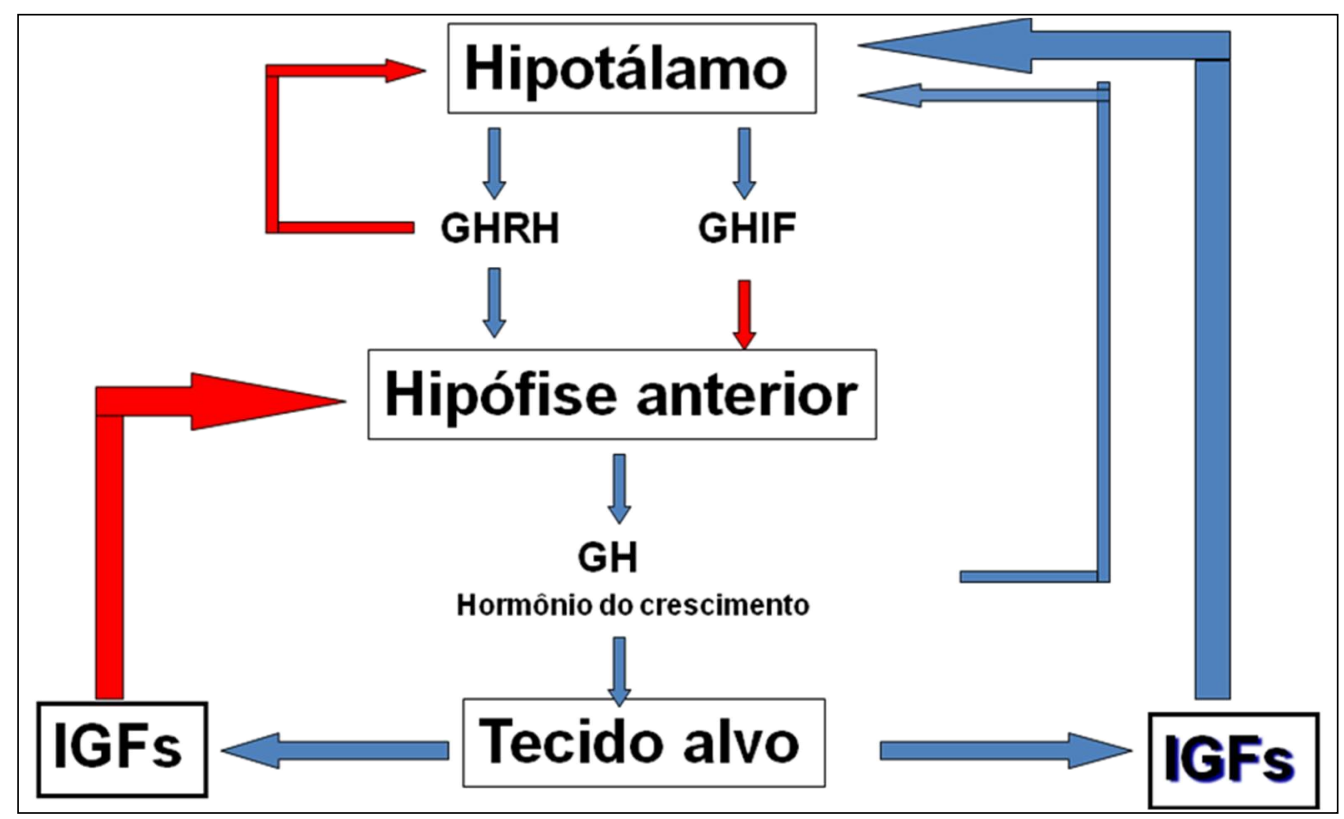

O IGF-I apresenta efeitos metabólicos similares à insulina, estimulando o crescimento em diferentes tecidos através da proliferação e da diferenciação celulares, é um mediador que também se destaca agindo nas cartilagens. Tais efeitos mitogênicos, diferentemente da insulina, são mediados através da ligação do IGF com uma proteína ligante de IGFs (IGFBPs); não interagindo, entretanto, somente com os receptores de IGF (IGF-R) (THISSEN et al., 1994; ULRICH et al., 1986), mas também com os de insulina (IR).

Sabe-se que o $\mathrm{GH}$ atua diretamente nos tecidos-alvo e indiretamente através da mediação pelo IGF-I (GREEN et al., 1985; HERINGTON et al., 1983; ISAKSSON et al., 1985) e que, além de induzir um aumento sistêmico do IGF-I, também tem efeito local na cartilagem de crescimento, onde é regulada a expressão local desse fator. Essas ações têm sido confirmadas por ensaios de hibridização in vitro em costelas (LIN; OBERAUER, 1999; NILSSON et al., 1990) e tíbia de ratos (LAZOWSKI et al., 1994; ONLEY; OUGEY, 1999, SJÖGREN et al., 1999). 
Trabalhos como os de Ohlsson et al. (2000) e de Rönning (1995) propõem que, para o crescimento geral, a produção de IGF-I de ação autócrina ou parácrina, é até mais importante do que o de ação endócrina. Porém, tanto o mecanismo de regulação da cartilagem secundária, como a observação dos IGF-IR diante de um estado nutricional modificado, são assuntos ainda não totalmente elucidados. Nas cartilagens primárias, apesar de alguns receptores de determinados fatores de crescimento já terem sido identificados nas epífises de ossos longos, também são escassas as informações a esse respeito, particularmente na $\mathrm{SB}$, uma representante desse tipo de cartilagem na região craniofacial (RÖNNING, 1995).

Fuentes et al. (2002) avaliaram, através de técnica de imunorreatividade, o IGFIR na cartilagem do PC de ratos. Não observaram reação na camada articular, sendo que os condrócitos da parte mais inferior da camada pré-condroblástica e os da parte mais superior da camada condroblástica, foram os que exibiram maior reatividade. Uma fraca imunorreatividade, expressa pela presença de poucos receptores, foi identificada na parte inferior da camada condroblástica e na superior da camada hipertrófica. Verificaram, ainda, um aumento na expressão gênica do IGF-I na transição entre os períodos pré-púbere (31dias) e púbere (42 dias), evidenciando que a proliferação da cartilagem do PC pode ser regulada em parte pelo IGF-I, e que a expressão destes genes muda consideravelmente durante a puberdade. Todavia, Visnapuu et al. (2001) detectaram, na cartilagem do $\mathrm{PC}$ de ratos no período compreendido entre o nascimento e 21 dias, os receptores de IGF-I nas camadas articular, pré-condroblástica e parte superior da hipertrófica, não encontrando nenhum receptor de $\mathrm{GH}$ no período estudado.

Os mecanismos que controlam a secreção de GH e consequentemente dos IGFs não são completamente compreendidos, sendo considerada inclusive a possibilidade do GH provocar a produção de IGF-I nos tecidos, possibilitando assim, a indução de um crescimento localizado (SILVERTHORN et al., 2003). Entretanto, sabe-se que diversos fatores relacionados com o estado nutricional estão envolvidos nesse processo (HILL et al., 1998) e que, frente a um estado de subnutrição protéico-calórica em condições crônicas, parece ser a depleção protéica mais comprometedora que a insuficiência de glicose, tornando o sistema de IGFs altamente responsivo a este tipo subnutrição, que por sua vez, atua estimulando a secreção do GH (CONSTANZO, 2004). 
Desta forma, na presente pesquisa, serão avaliados os efeitos da subnutrição protéica severa (REEVES et al., 1993) no crescimento do PC e da SB através da detecção do IGF-I e seu receptor (IGF-IR), uma vez que tem sido relatado, que sob condições graves de subnutrição protéica, há um excesso de produção de $\mathrm{GH}$ (PIMSTONE et al., 1968). 
2 PROPOSIÇÃO 


\subsection{GERAIS}

Avaliar no processo condilar (PC) e na sincondrose basiesfenoidal (SB) de ratos Wistar na fase púbere (60 dias), os efeitos da subnutrição protéica pré e pós-natal.

\subsection{ESPECÍFICAS}

Determinar, com o uso de técnicas de histologia, a quantidade de matriz extracelular, a morfometria das camadas e os tipos de fibras colágenas constituintes do PC e da SB. Investigar, nessas estruturas, através de técnicas de imunohistoquímica, a expressão do fator de crescimento semelhante à insulina do tipo I (IGF-I) e do seu receptor (IGF-IR). 
Esta seção compreende a descrição detalhada, em ordem cronológica, da metodologia aplicada na presente pesquisa.

\subsection{FORMAÇÃO DOS GRUPOS EXPERIMENTAIS}

Foram utilizados ratos machos e fêmeas da linhagem Wistar (Rattus norvegicus) com aproximadamente 60 dias de vida e peso entre 200 e $320 \mathrm{~g}$. Durante o período de acasalamento (7 a 10 dias), um macho e duas fêmeas foram acomodados na mesma caixa, mantidos em sala com ciclos de claro e escuro de 12 horas e temperatura ambiente de $22{ }^{\circ} \mathrm{C} \pm 2{ }^{\circ} \mathrm{C}$. Nessa fase, um grupo de animais denominado nutrido $(\mathrm{N})$ passou a receber a ração AIN-93G (Rhoster, Araçoiaba da Serra, SP., Brasil) (REEVES, et al., 1993) com $20 \%$ de caseína, e para o grupo subnutrido (S) forneceuse a mesma ração, com teor protéico de $5 \%$ de caseína.

Findo esse período, as fêmeas foram separadas em gaiolas individuais onde continuaram a receber as respectivas rações, até o nascimento da prole. Após o nascimento, as ninhadas foram reduzidas a um número mínimo de 4 e máximo de 6 animais, desprezando-se os excedentes, e as ninhadas cujas mães alimentaram-se dos filhotes. Durante todo o período de amamentação as mães e os filhotes foram mantidos com as respectivas dietas e, após o $21^{\circ}$ dia de vida, época do fim do desmame, os filhotes machos $\mathrm{N}$ e $\mathrm{S}$ foram separados e monitorados individualmente em gaiolas metabólicas (Tecniplast, Buguggiate, VA., Itália) até atingirem 60 dias de vida (Figuras 2 e 3). 
Figura 2 - Esquema representativo da formação dos grupos.
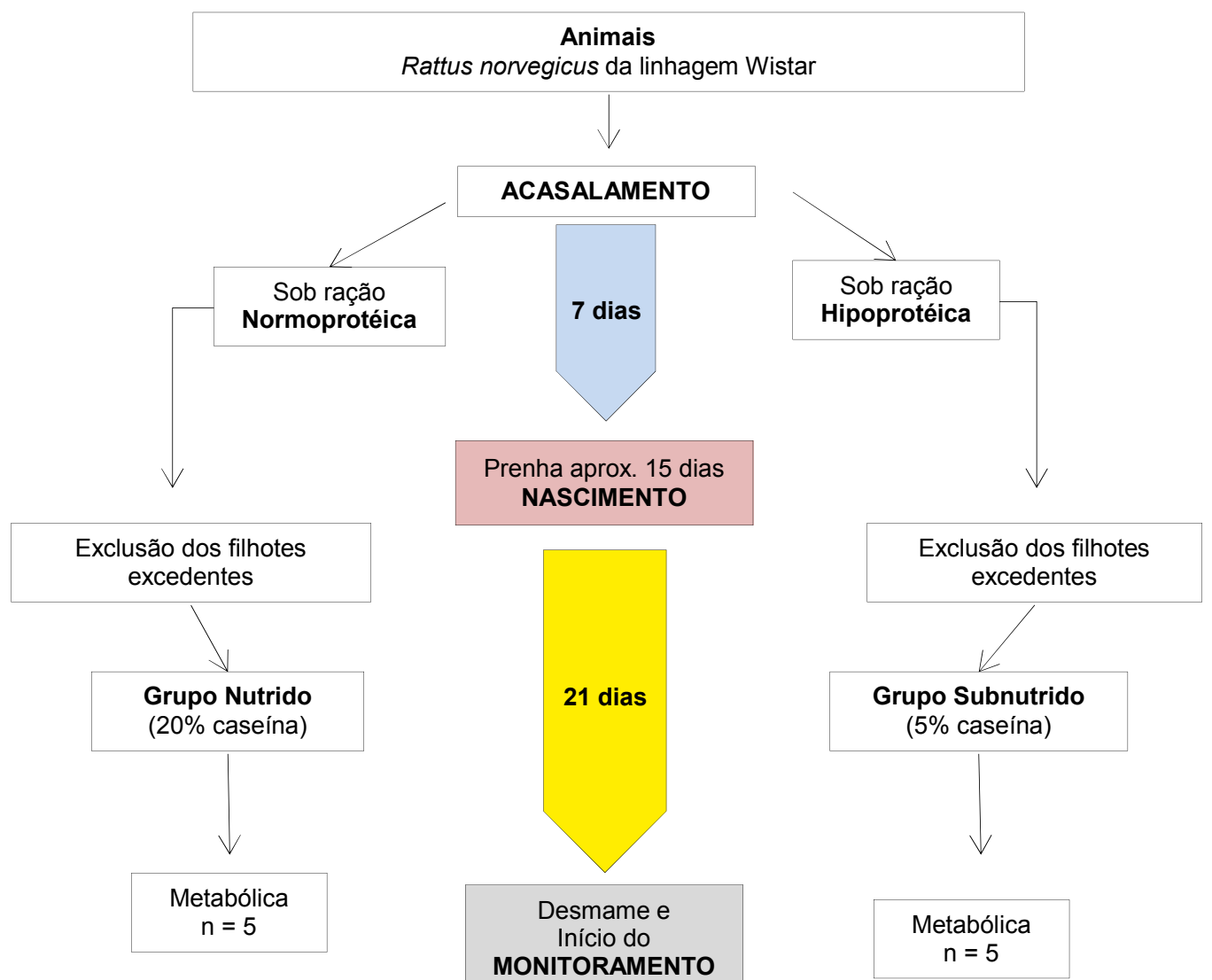

Metabólica

Início do

MONITORAMENTO

Metabólica

$$
n=5
$$

\section{Eutanásia no} $60^{\circ} \mathrm{dia}$

Fonte: Adaptado (BAPTISTA, 2008). 
Figura 3 - Imagens da estante (A) e da gaiola metabólica individualizada (B)
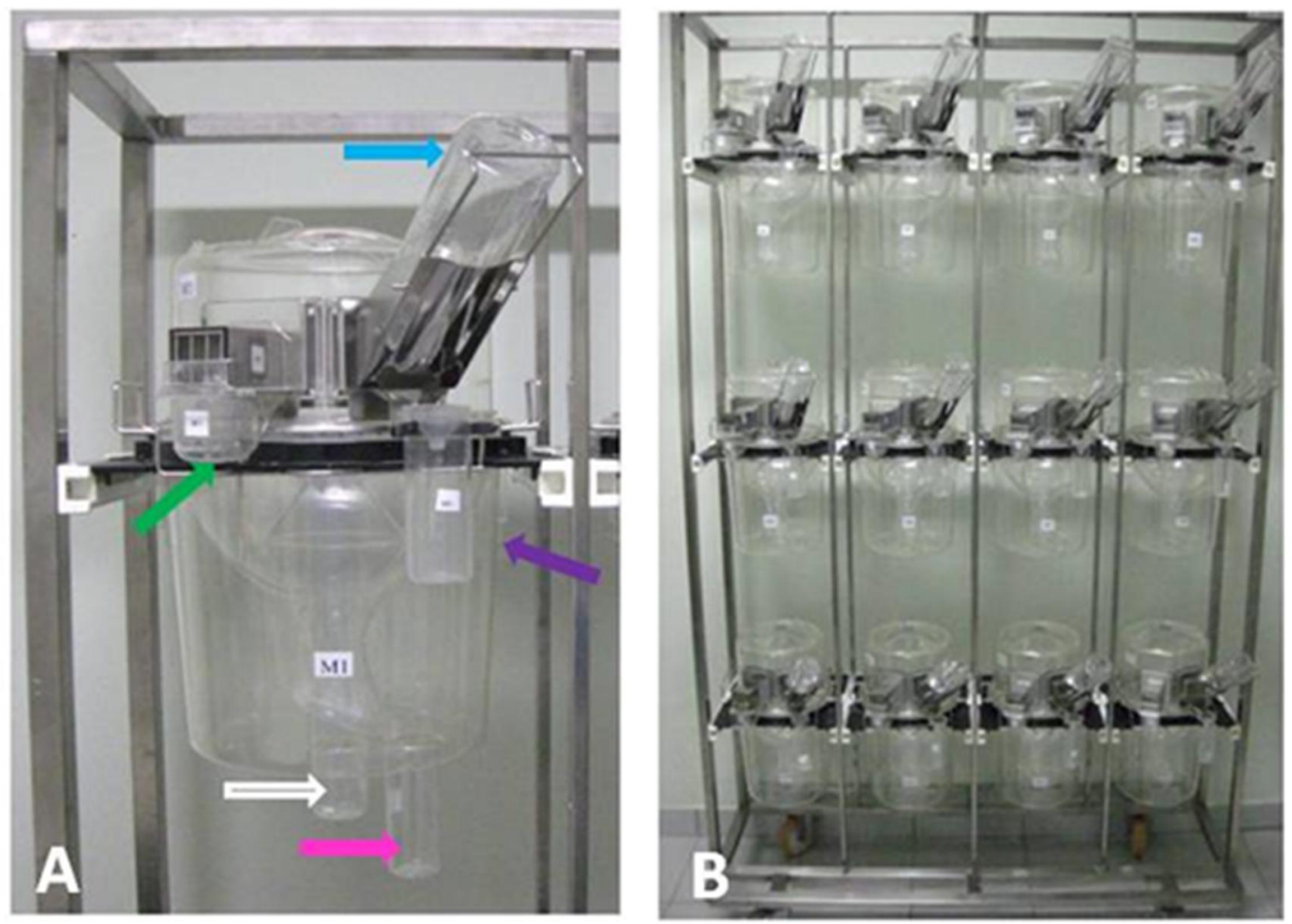

Fonte: LUIZ, 2012.

Gaiola individualizada com seus recipientes detalhados pelas setas: para o abastecimento de água (azul), para acondicionamento e coleta de ração desperdiçada (verde), tubo coletor de urina (rosa), tubo coletor de fezes (branca) e água dispensada (roxa) (A). Estante com 12 gaiolas metabólicas (B)

\subsection{OBTENÇÃO DOS ESPÉCIMES}

Cinco animais não isogênicos de cada grupo ( $\mathrm{N}$ e $\mathrm{S}$ ) foram eutanasiados com Hypnol (Syntec, Cotia, SP., Brasil) a 3\% (Pentobarbital sódico - 30mg/Kg de peso corporal), e tiveram retirados $\mathrm{O} P \mathrm{PC}$ e a $\mathrm{SB}$, com o auxílio de pinças e tesouras oftalmológicas (Figura 4 e 5). 
Figura 4 - Etapas para a obtenção do processo condilar da mandíbula (PC).
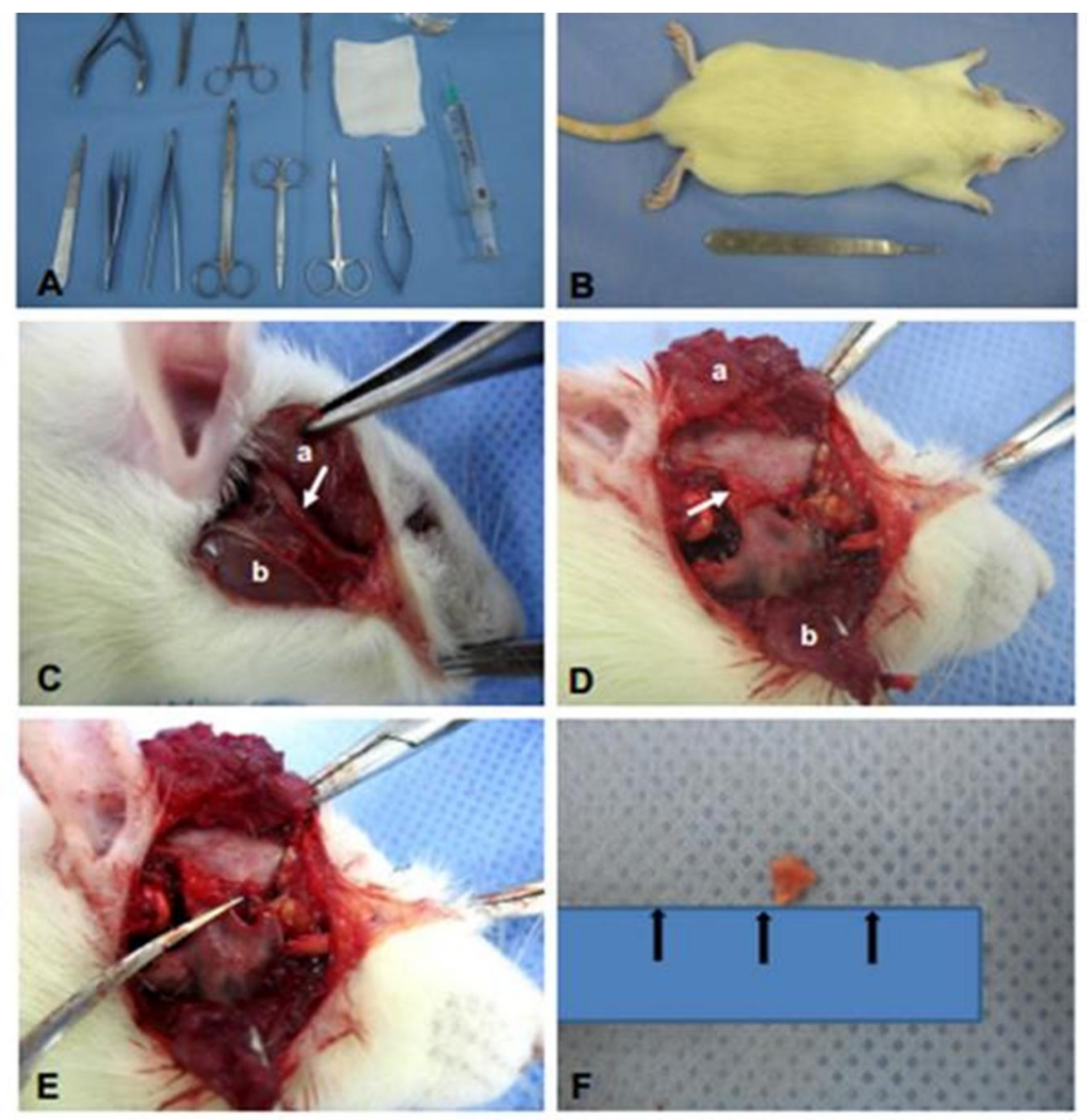

Fonte: CAVALLI, 2011.

Mesa cirúrgica (A); Vista dorsal do animal (B); Abertura pré-auricular com exposição do mm. Temporal (a) e masseter (b) e do arco zigomático (seta) (C); Evidenciação da cápsula da ATM (D) (seta) após o rebatimento do arco zigomático e mm. temporal (a) e masseter (b); Abertura da cápsula articular (E); PC em vista lateral (F). 
Figura 5 - Etapas para a obtenção da sincondrose basiesfenoidal (SB).
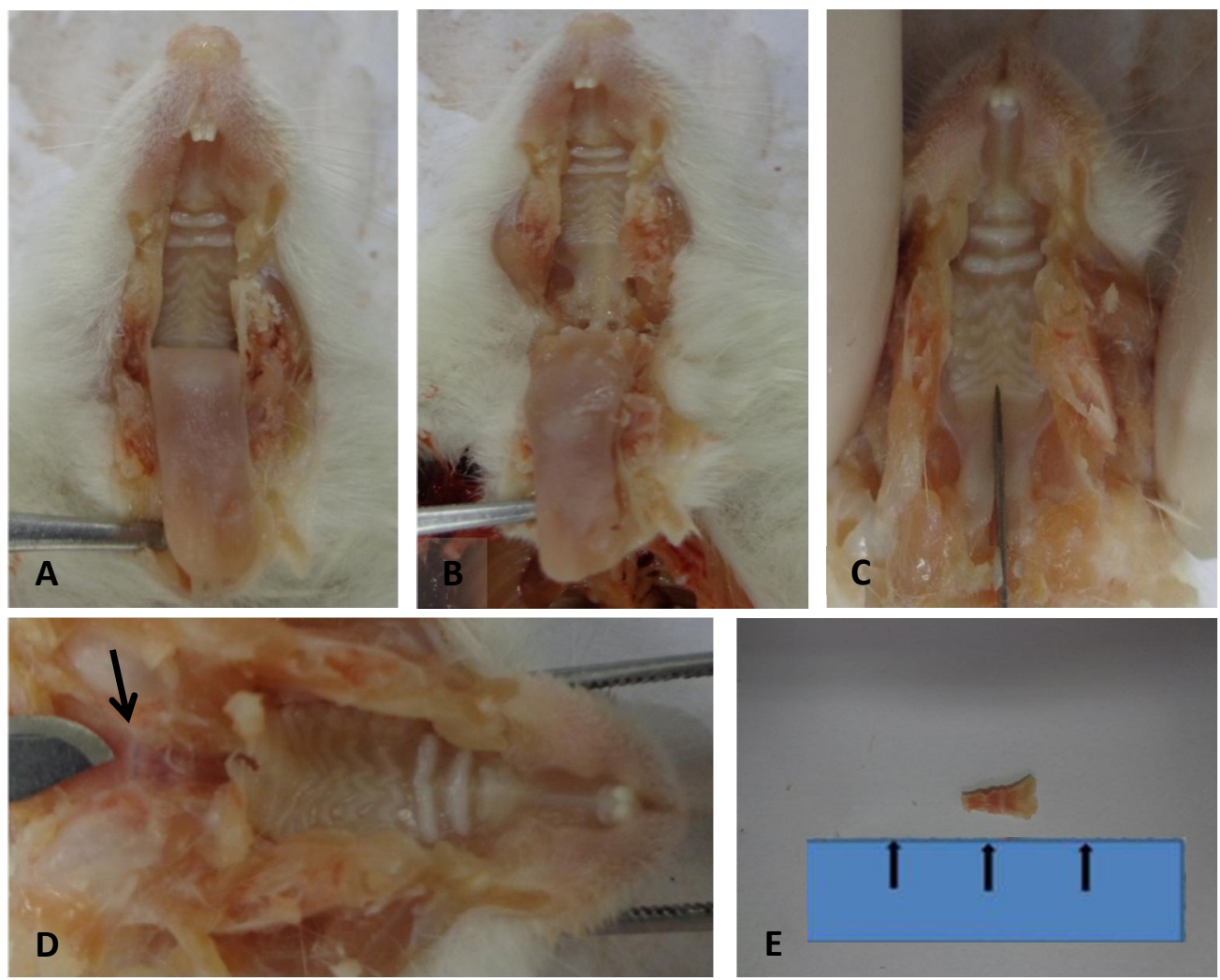

Remoção da mandíbula com exposição do palato (A); Evidenciação da base do crânio (B e C); Exposição da SB (D); SB em vista inferior (E).

Em seguida, os espécimes foram fixados em Bouin (STEFANINI et al., 1967) por 8 horas e descalcificados, durante 30 dias, em solução de ácido fórmico (50\%) e citrato de sódio (20\%) (MORSE, 1945), com trocas periódicas de 48 horas.

Após testes de avaliação do conteúdo mineral das amostras que confirmaram a completa descalcificação dos espécimes (solução de oxalato de amônio em $5 \%$ de Morse), os mesmos foram lavados em água destilada, desidratados numa série crescente de álcoois $\left(70^{\circ}\right.$ ao absoluto), diafanizados em xilol e incluídos rotineiramente em parafina. Cortes semi-seriados de $5 \mu \mathrm{m}$ foram realizados em micrótomo (Leica SM 200R) nos planos sagital dos PCs e horizontal das SBs, e mantidos em estufa a $37^{\circ} \mathrm{C}$, para desparafinização. 
As lâminas contendo em média 5 cortes de cada espécime foram submetidas às técnicas descritas a seguir.

\subsection{HISTOLOGIA}

$\mathrm{Na}$ morfometria das camadas, a avaliação da matriz extracelular (MEC), bem como a tipificação das fibras colágenas do PC e da SB foram avaliadas com o uso, respectivamente, das técnicas de azo-carmim (Sigma-Aldrich, St. Louis, MO.,Estados Unidos) (ROMEIS, 1968); safranina-O (LUNA, 1968) e Picrosírius (JUNQUEIRA, 1979).

\subsubsection{Azo-carmin}

As lâminas permaneceram no corante por 20 minutos e em seguida, por 10 minutos na água destilada. Após a lavagem, foram imersas por 10 minutos em solução de ácido fosfotungístico a $5 \%$, e posteriormente, no azul de anilina a $1 \%$ pelo mesmo período. Em seguida, os cortes foram desidratados em série crescente de álcoois $\left(70^{\circ}\right.$ ao absoluto), diafanizados em xilol e montados com Enthelan (Merck S.A., Darmstadt, Alemanha) entre lâmina e lamínula.

\subsubsection{Safranina-O}

Essa metodologia, que confere à MEC diferentes tonalidades de vermelho de acordo com o teor protéico da cartilagem, consiste na diafanização das lâminas em xilol, por duas vezes num tempo de 7 minutos; hidratação por duas vezes do etanol de 100\% para 95\% (2 minutos cada); lavagem em água destilada e imersão por 10 minutos na solução de safranina (Sigma-Aldrich) a 0,1\% em tampão acetato de sódio (0,1M; pH 4,6). Após desidratação (etanol 95\% e 100\%, 2 minutos cada e xilol por duas vezes, 7 minutos cada), as lâminas foram montadas conforme descrito no item anterior (3.3.1). 


\subsubsection{Picrosírius}

Para a tipificação das fibras colágenas (I, II e III) os cortes foram imersos no corante Sirius Red por um período de 25 minutos e em seguida, lavados em água destilada, desidratados, diafanizados e montados de acordo com o item 3.3.1. A avaliação foi realizada em microscópio binocular (Carl Zeiss, Göttingen, Alemanha), sob luz polarizada.

\subsection{IMUNOHISTOQUÍMICA PARA O IGF-I E PARA O IGF-IR}

As lâminas foram processadas nas seguintes etapas: rehidratação desde o xilol até uma série decrescente de álcoois (do absoluto ao $50^{\circ}$ ), por 2 minutos cada e, em seguida, lavadas em água destilada por 5 minutos, e expostas pelo mesmo tempo em peróxido de hidrogênio à $3 \%$. Após a lavagem em solução de fosfato de Sódio tamponado (PBS) as mesmas foram incubadas em soro normal de cabra na proporção 1:5 por 30 minutos, em temperatura ambiente. Para a marcação, respectivamente do IGF-I e do IGF-IR foram utilizados, em lâminas diferentes, os anticorpos anti-IGF-I e anti-IGF-IR (Santa Cruz Biotechnology, Dallas, TX., Estados Unidos das Américas) na diluição 1:250 que, por prévia titulação, foi considerada a mais adequada. Em seguida, à temperatura ambiente, as lâminas foram incubadas com o anticorpo primário por um período de 2 horas, lavadas em PBS $(4 \times 10 \mathrm{~min})$ e incubadas por 30 minutos com anticorpo secundário de cabra anti-coelho IgG (Bio Rad, Hercules, CA., Estados Unidos das Américas) na diluição de 1:200. Após lavadas em solução de Triton $(0,01 \%$ em PBS) as lâminas foram incubadas durante 30 minutos com Vectain $A B C$ (1:100), (Vector Laboratories, Burlingame, CA., Estados Unidos das Américas) lavadas em PBS (5 minutos), incubadas com DAB por 8 minutos (Vector) e finalmente, lavadas em água destilada, desidratadas, diafanizadas e montadas rotineiramente. Todas as reações foram acompanhadas por uma ou mais lâminas controle, submetidas a todas as etapas do procedimento suprimindo-se, entretanto, a aplicação do anticorpo primário. 


\subsection{ESTUDO QUANTITATIVO}

Imagens das lâminas preparadas pelas diferentes técnicas foram obtidas através de um microscópio binocular (Carl Zeiss, Axioshop, Göttingen, Alemanha) e projetadas através de uma câmera de alta resolução (Carl Zeiss) em um monitor de 17 polegadas, a fim de que se avaliar por meio de software especializado (Carl Zeiss) os parâmetros seguir.

\subsubsection{Espessura das camadas do PC e da SB}

A espessura das camadas do PC e da SB foram determinadas na região média dessas estruturas, com objetivas de 40x de aumento, conforme ilustram as figuras 6 e 7. 
Figura 6 - Fotomicrografia da parte média do PC.

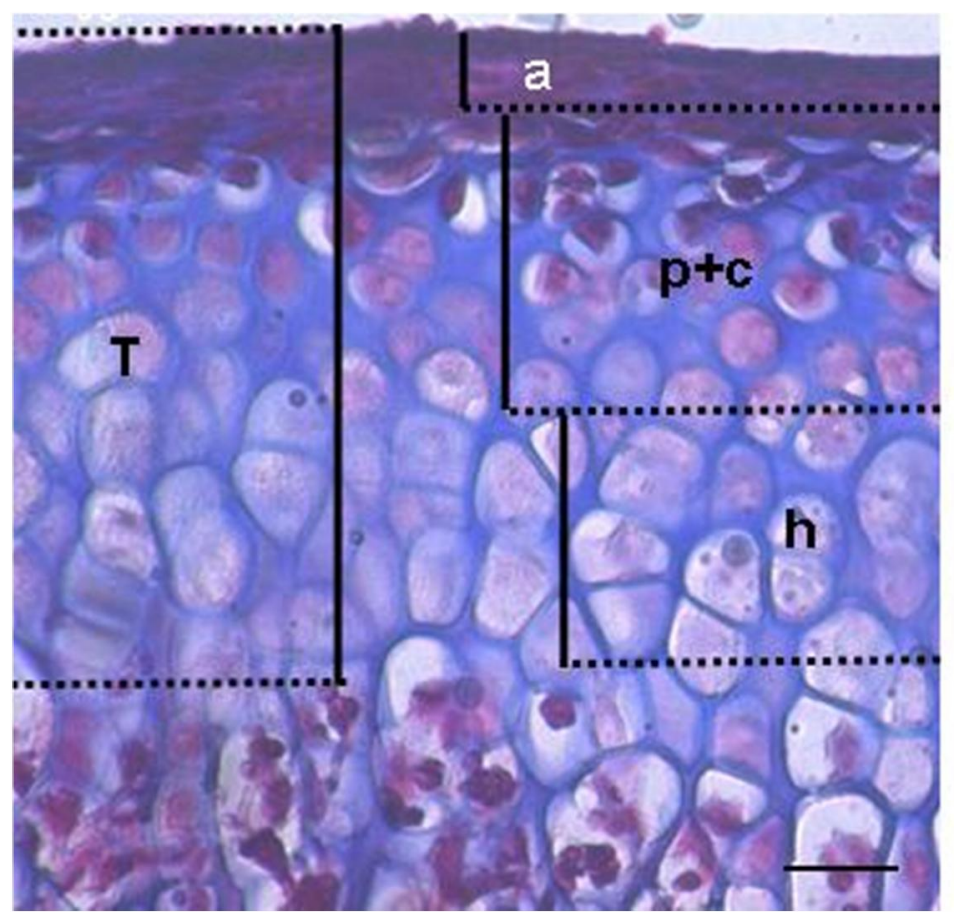

Observe a metodologia empregada para a obtenção das diferentes espessuras da cartilagem articular. (T- espessura total; a- camada articular; p+c- camadas pré-condroblástica e condroblástica; $\mathbf{h}$ - camada hipertrófica). (Azo-carmin. Barra de calibração: $40 \mu \mathrm{m}$ ) 
Figura 7 - Fotomicrografia da parte média da SB.

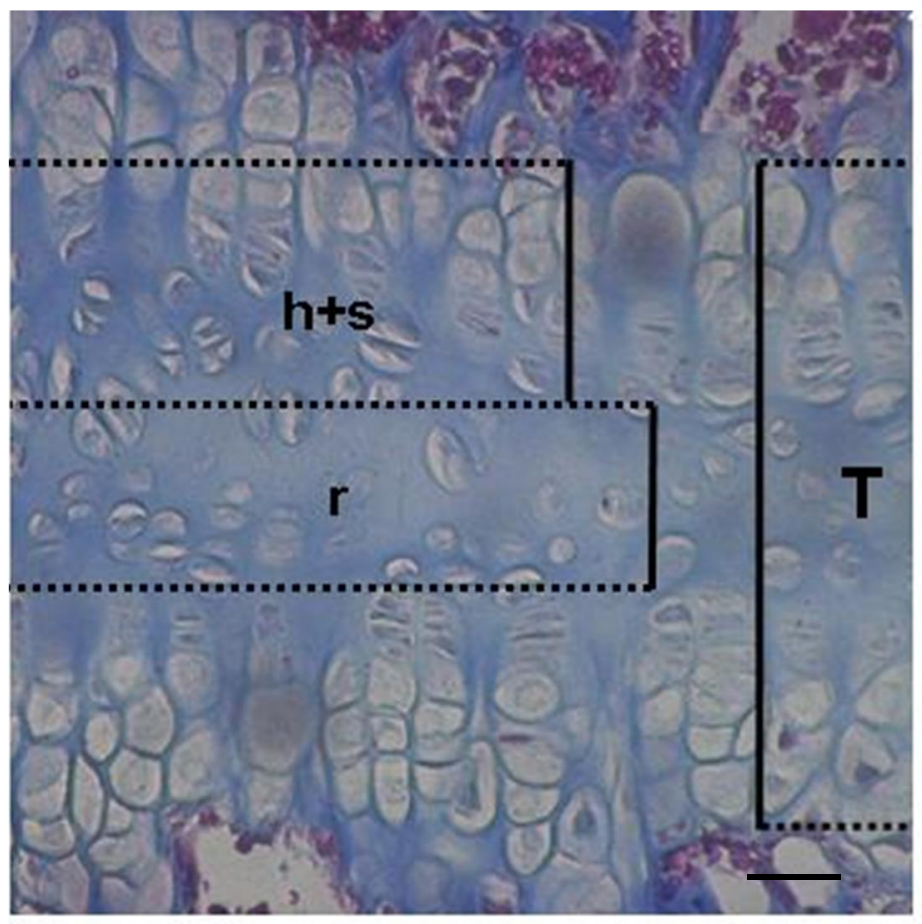

Observar a metodologia empregada para a obtenção das diferentes espessuras da cartilagem articular. (T- espessura total; $\mathbf{h}+\mathbf{s}$ - camadas hipertrófica e seriada; $\mathbf{r}$ - camada de repouso). (Azocarmin. Barra de calibração: $40 \mu \mathrm{m}$ ).

\subsubsection{Número de células imunomarcadas nas cartilagens do PC e da SB.}

Em imagens obtidas com objetiva de 40x da parte média do PC e da SB das lâminas imunomarcadas pelo IGF-I e pelo IGF-IR, foi aplicado um acetato com três áreas delimitadas, cujo formato variou de acordo com a estrutura analisada, ou seja, elíptica para o PC e retangular para a SB, conforme se verifica nas figuras 8 e 9 . 
Figura 8 - Fotomicrografias da parte média do PC.

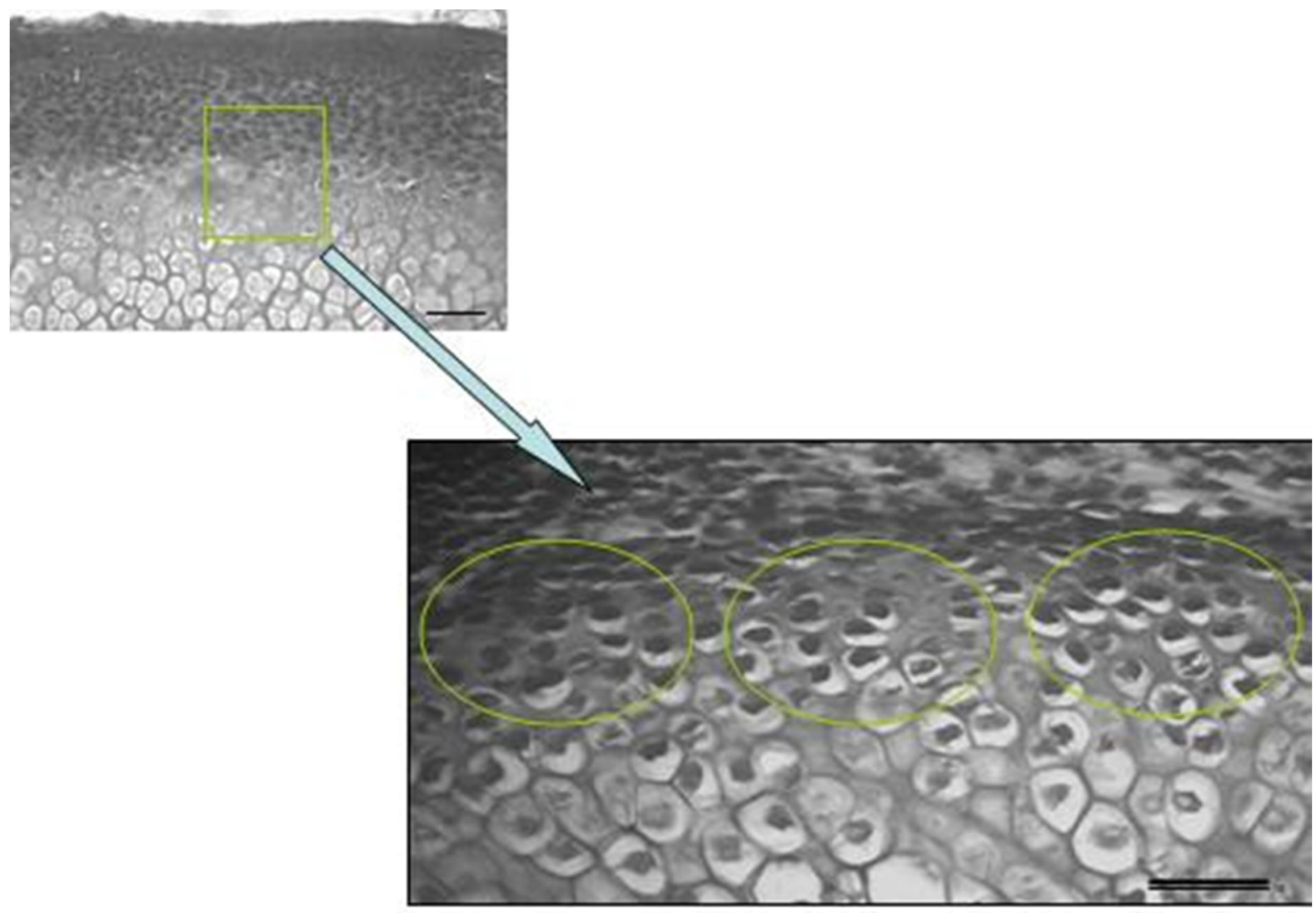

Observar a delimitação dos campos determinados para a contagem do número de células imunorretativas ao IGF-I e ao IGF-IR. (Barra de calibração: superior: $20 \mu \mathrm{m}$; inferior: $40 \mu \mathrm{m}$ ). 
Figura 9 - Fotomicrografias da parte média da SB

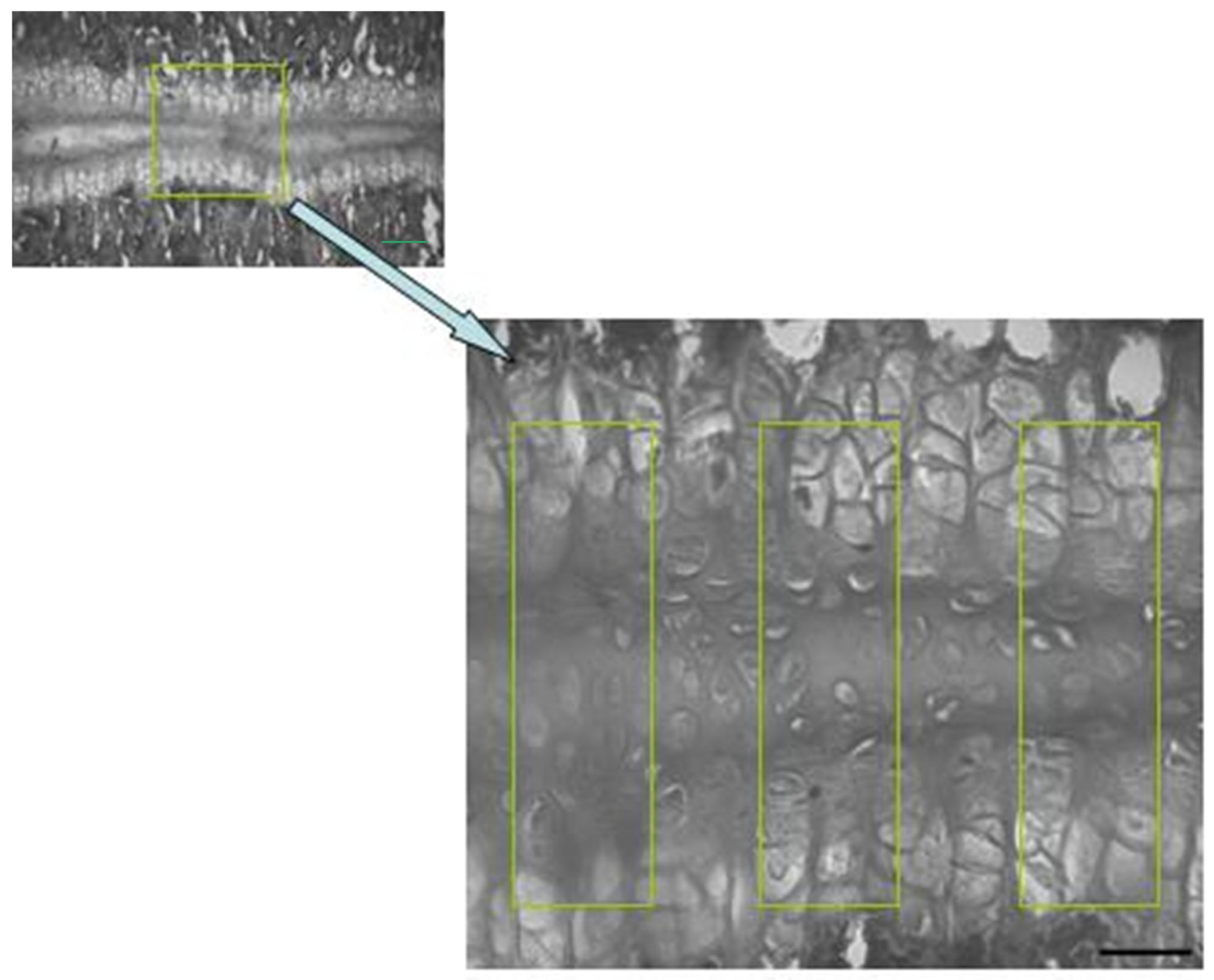

Observar a delimitação dos campos determinados para a contagem do número de células imunorretativas ao IGF-I e ao IGF-IR. (Barra de calibração: superior: $20 \mu \mathrm{m}$; inferior: $40 \mu \mathrm{m}$ ). 


\subsection{TRATAMENTO ESTATÍSTICO}

Os dados obtidos nos itens referentes à quantificação foram submetidos a uma análise da variância com 1 fator (grupo), seguida por comparações múltiplas pelo método de Tukey, com nível de significância $p<0.05$. 
4 RESULTADOS 
Os resultados obtidos serão ordenados e organizados pelos tópicos: Análise Quantitativa e Qualitativa, respectivamente.

\subsection{ANÁLISE QUANTITATIVA}

Os dados obtidos para as medidas das espessuras das camadas do PC e da SB, bem como para a densidade de condrócitos imunorreativos ao IGF-I e ao IGF-IR serão descritos a seguir.

\subsubsection{Espessuras das camadas}

A tabela 1 e a figura 10 ilustram os dados obtidos para esses parâmetros nas camadas articular, pré-condroblástica com a condroblástica, e hipertrófica do PC, onde não foram observadas diferenças estatísticas entre os grupos, em todas as medidas determinadas.

Tabela 1 - Espessuras das camadas do PC nos grupos Nutrido (N) e Subnutrido (S).

\begin{tabular}{ccccc}
\hline Parâmetros & $\mathbf{T}$ & $\mathbf{a}$ & $\mathbf{p + c}$ & $\mathbf{h}$ \\
\hline $\mathbf{N}$ & $249,2 \pm 26,7$ & $13,3 \pm 2,2$ & $111,6 \pm 16,2$ & $121,3 \pm 20,7$ \\
\hline $\mathbf{S}$ & $195,1 \pm 30,5$ & $14,3 \pm 0,8$ & $85,5 \pm 22,4$ & $95,4 \pm 12,6$ \\
\hline
\end{tabular}

Média \pm desvio padrão em $\mu \mathrm{m}$ (T- Total; $\mathbf{a}$ - articular; $\mathbf{p}+\mathbf{c}$ - pré-condroblática com a condroblástica; $\mathbf{h}$ - hipertrófica). 
Figura 10 - Representação gráfica das medidas das espessuras obtidas para as camadas do PC.

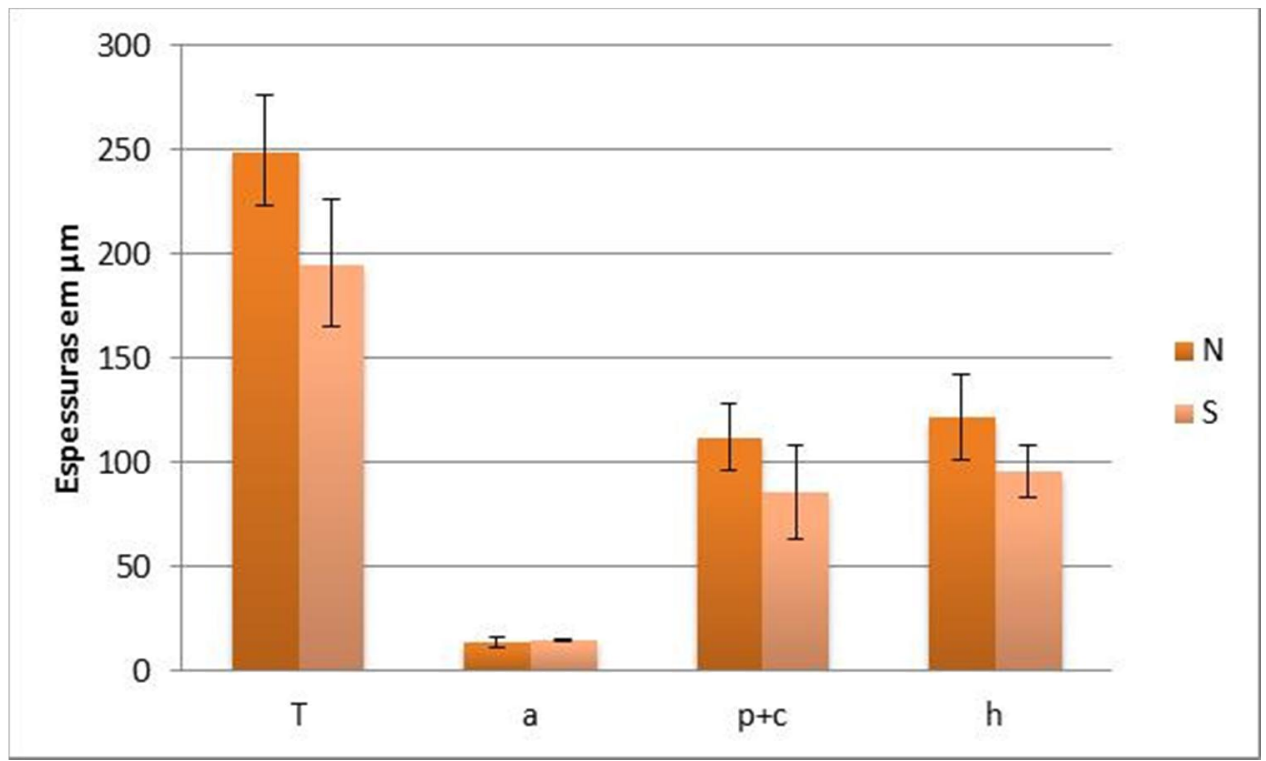

Notar que não ocorrem diferenças estatísticas entre os grupos $\mathrm{N}$ e S nos diferentes parâmetros avaliados.

$\mathrm{Na}$ tabela 2 e figura 11 estão expressos os valores das medidas obtidas nas diferentes camadas da SB. Da mesma forma que para o PC, não foram detectadas diferenças estatísticas significantes entre os grupos, em todas as camadas estudadas.

Tabela 2 - Espessuras das camadas da SB nos grupos Nutrido (N) e Subnutrido (S).

\begin{tabular}{cccc}
\hline Parâmetros & $\mathbf{T}$ & $\mathbf{h}+\mathbf{s}$ & $\mathbf{r}$ \\
\hline $\mathbf{N}$ & $330,6 \pm 24,0$ & $121,5 \pm 7,8$ & $91,6 \pm 12,7$ \\
$\mathbf{S}$ & $316,4 \pm 20,02$ & $110,2 \pm 8,9$ & $103,8 \pm 12,1$ \\
\hline
\end{tabular}

Média \pm desvio padrão $(\mathrm{em} \mu \mathrm{m})$ das espessuras (T- Total; $\mathbf{h}+\mathbf{s}$ - hipertrófica com seriada; $\mathbf{r}$ repouso). 
Figura 11 - Representação gráfica das medidas das espessuras obtidas para as camadas da SB.

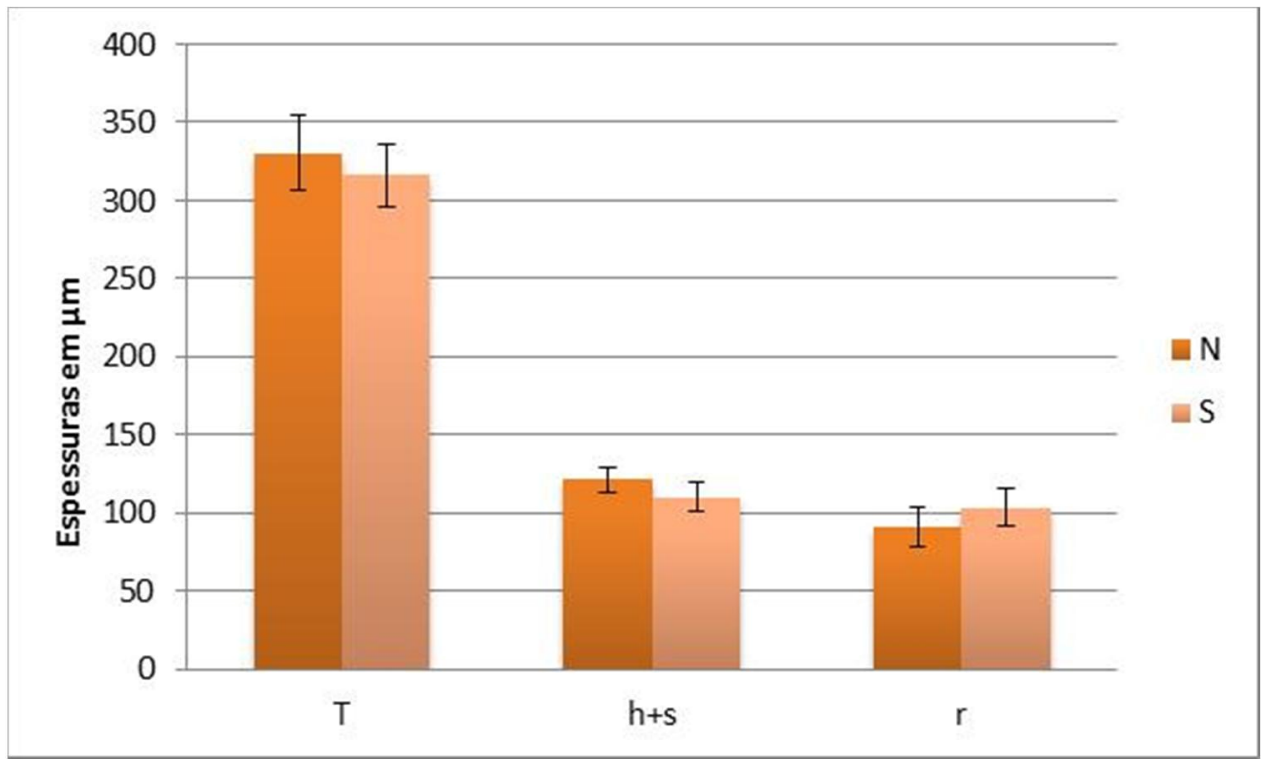

Verificar que não ocorreram diferenças estatísticas entre os grupos $\mathrm{N}$ e $\mathrm{S}$ nos diferentes parâmetros avaliados.

\subsubsection{Densidade de células imunorreativas}

As densidades médias de condrócitos imunorreativos determinadas para a parte média do $\mathrm{PC}$ nos grupos nutrido $(\mathrm{N})$ e subnutrido $(\mathrm{S})$ podem ser avaliadas na tabela $3 \mathrm{e}$ figura 12. Verificou-se que, tanto para o IGF-I como para o IGF-IR, a densidade dessas células foi maior no grupo nutrido $(\mathrm{N})$. 
Figura 12 - Micrografias de cortes do PC (A) e da SB (B) imunomarcadas pelo IGF-I e o IGF-IR.
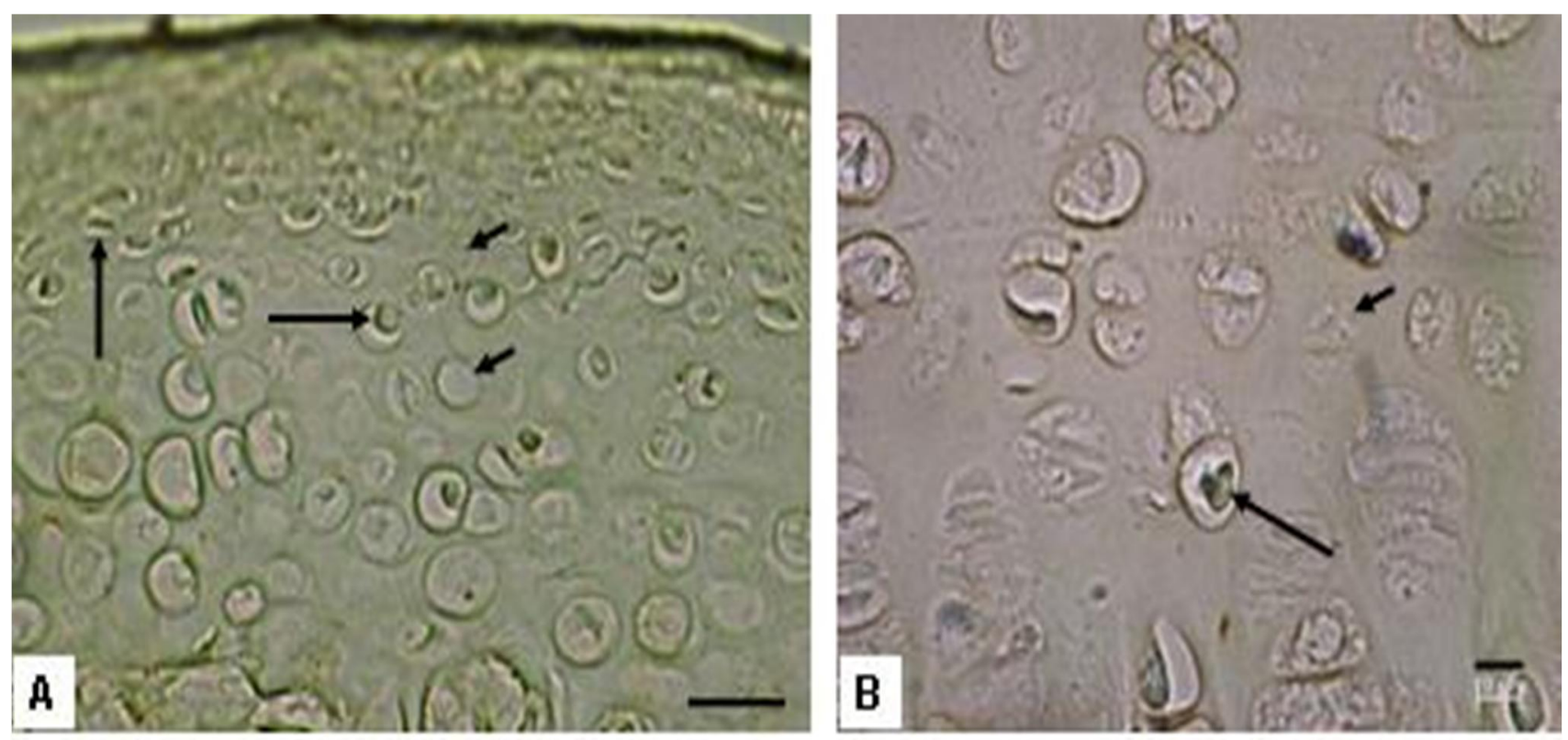

Notar as células imunomarcadas (setas longas) destacando-se das que não sofreram reação (setas curtas). (Barra de calibração: A- $20 \mu \mathrm{m} ; \mathrm{B}-10 \mu \mathrm{m}$ ).

Tabela 3 - Densidade de condrócitos imunorreativos do PC.

\begin{tabular}{ccc}
\hline Parâmetros & $\mathbf{N}$ & $\mathbf{S}$ \\
\hline IGF-I & $677,3 \pm 28,8^{*}$ & $524,5 \pm 45,3^{*}$ \\
\hline IGF-IR & $846,9 \pm 159,7^{*}$ & $502,8 \pm 45,0^{*}$ \\
\hline & \\
\hline \multicolumn{2}{l}{ Médias seguidas por um asteriscos se diferenciam estatisticamente ANOVA $(\mathrm{P}<0,05)}$.
\end{tabular}

Média \pm desvio padrão na cartilagem do PC dos animais dos grupos nutrido $(\mathrm{N})$ e subnutrido (S). 
Figura 13 - Densidade do número de células imunomarcadas no PC

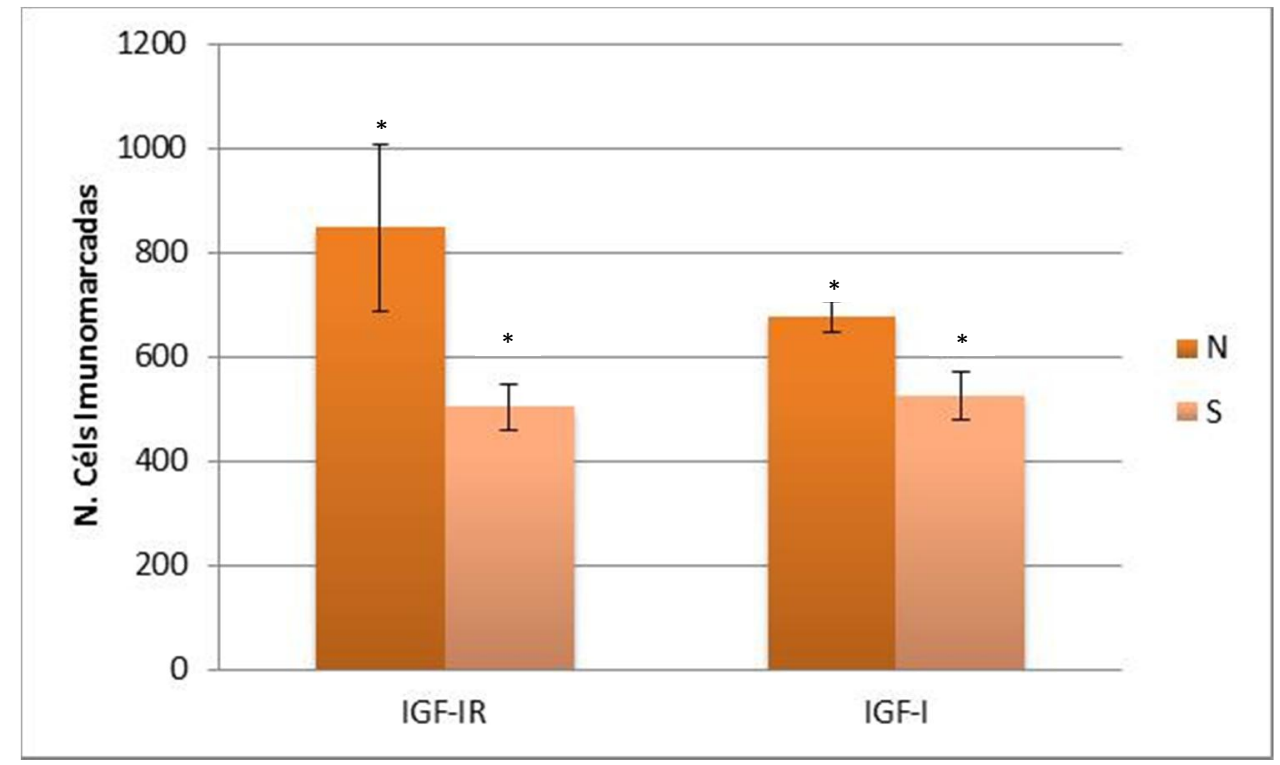

Cartilagem do PC imunomarcada pelos anticorpos IGF-I e o IGF-IR dos grupos estudados, onde se verifica uma maior densidade nos animais do grupo nutrido.

$\mathrm{Na}$ tabela 4 e figura 13 são observados os dados relativos às médias da densidade de células imunorreativas pelo IGF-I e IGF-IR detectadas na parte média da cartilagem da SB. A análise estatística permitiu verificar que, também nessa estrutura, a densidade maior dessas células foi observada nos animais do grupo nutrido $(\mathrm{N})$.

Tabela 4 - Densidade de condrócitos na parte média da SB.

\begin{tabular}{ccc}
\hline Parâmetros & N & S \\
\hline IGF-I & $396,2 \pm 19,8^{*}$ & $243,5 \pm 19,8^{*}$ \\
\hline IGF-IR & $423,1 \pm 55,2^{*}$ & $241,6 \pm 35,5^{*}$ \\
\hline
\end{tabular}

Média \pm desvio padrão dos condrócitos imunorreativos detectados nos animais dos grupos nutrido $(\mathrm{N})$ e subnutrido $(\mathrm{S})$. 
Figura 14 - Densidade do número de células imunomarcadas na SB.

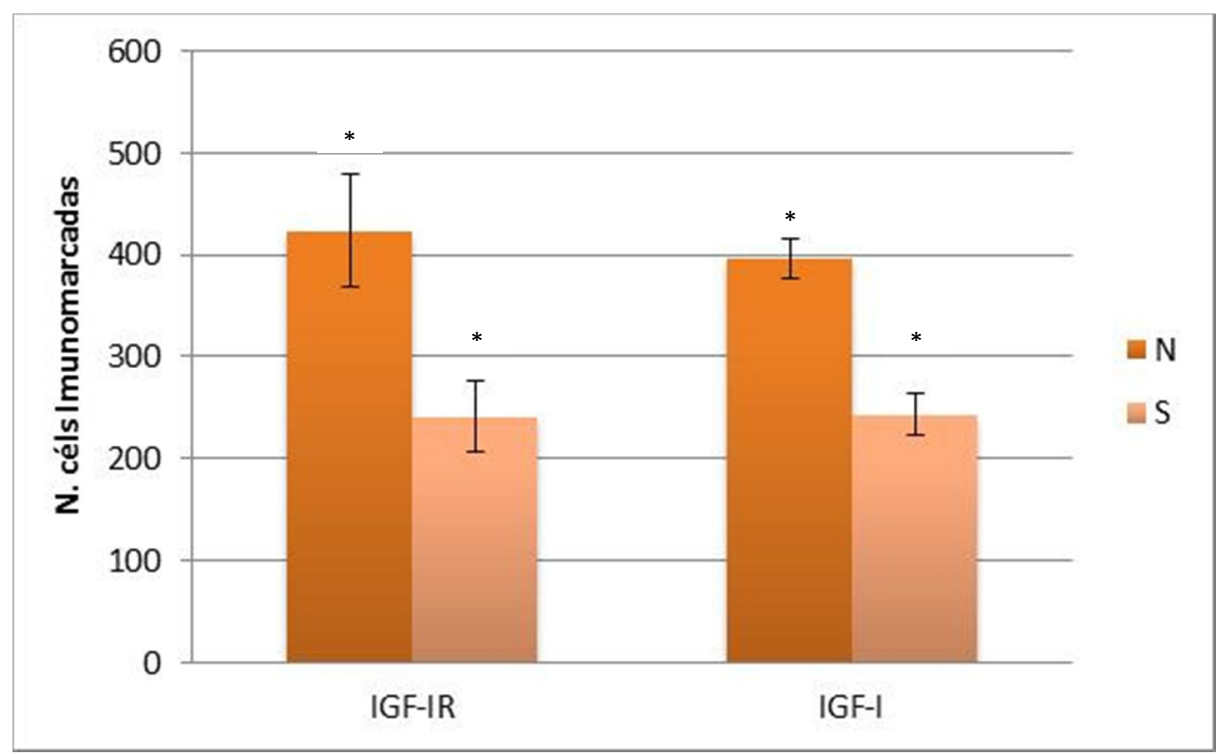

Parte média da SB imunomarcada pelos anticorpos IGF-I e IGF-IR dos grupos estudados, onde se verifica uma maior densidade nos animais do grupo nutrido.

\subsection{ANÁLISE QUALITATIVA}

O arcabouço estrutural, bem como a densidade da MEC analisados, respectivamente, pela tipificação das fibras colágenas através da metodologia do Picrosírius e pela coloração da Safranina-O permitiram verificar algumas diferenças entre os grupos, no PC e na SB.

Desta forma, ao se analisar na figura 14 o PC, sob luz polarizada, verificou-se no grupo $\mathrm{N}$ uma nítida predominância das fibras colágenas do tipo I (nas cores vermelha, laranja e amarela), ao passo que nos animais do grupo $\mathrm{S}$, destacou-se uma densidade maior de fibras colágenas do tipo III (na cor verde). 
Figura 15 - Fibras colágenas constituintes do PC dos animais nutridos $(A)$ e subnutridos (B).
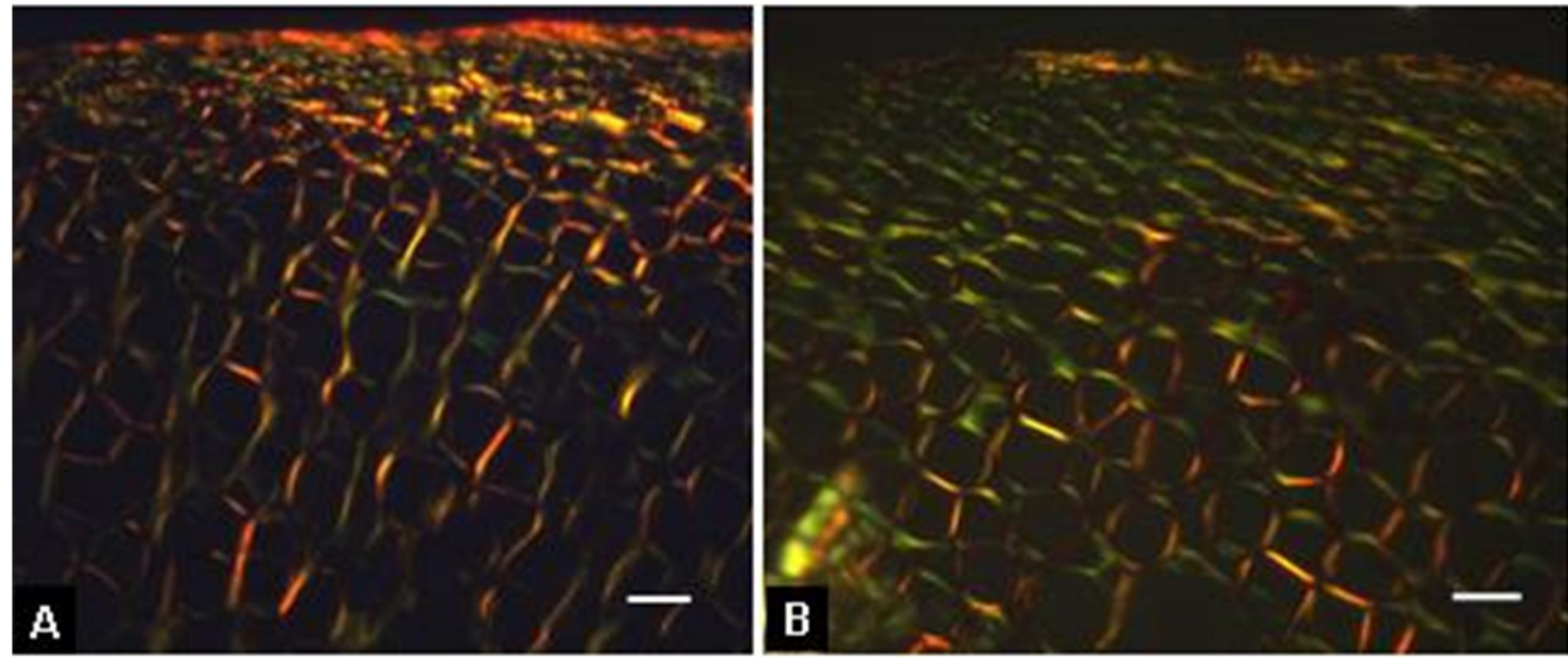

Observe a predominância de fibras do tipo I no grupo N,e do tipo III no grupo S. (Picro-sirius sob luz polarizada. Barra de calibração: $10 \mu \mathrm{m}$ ).

$\mathrm{Na}$ SB, pelo fato da sua estrutura ser composta por cartilagem hialina, as fibras colágenas que se destacam na sua constituição são, principalmente, as do tipo II que, de acordo com a estrutura analisada, assume uma coloração variando do verde ao azul. Quando se compara os grupos N e S quanto a esse aspecto, verifica-se uma maior densidade dessas fibras na SB dos animais nutridos, preenchendo quase que a totalidade do espaço interósseo ocupado pela mesma; ao contrário, a densidade dessas fibras no grupo $S$ encontra-se principalmente na periferia desse espaço, em continuidade com os ossos que constituem o limite dessa região. Nesse grupo, há uma grande quantidade de loci dos condrócitos, que se apresentam em número bem menos no grupo N (Figura 16). 
Figura 16 - Fibras colágenas constituintes da SB dos animais nutridos (A) e subnutridos (B).
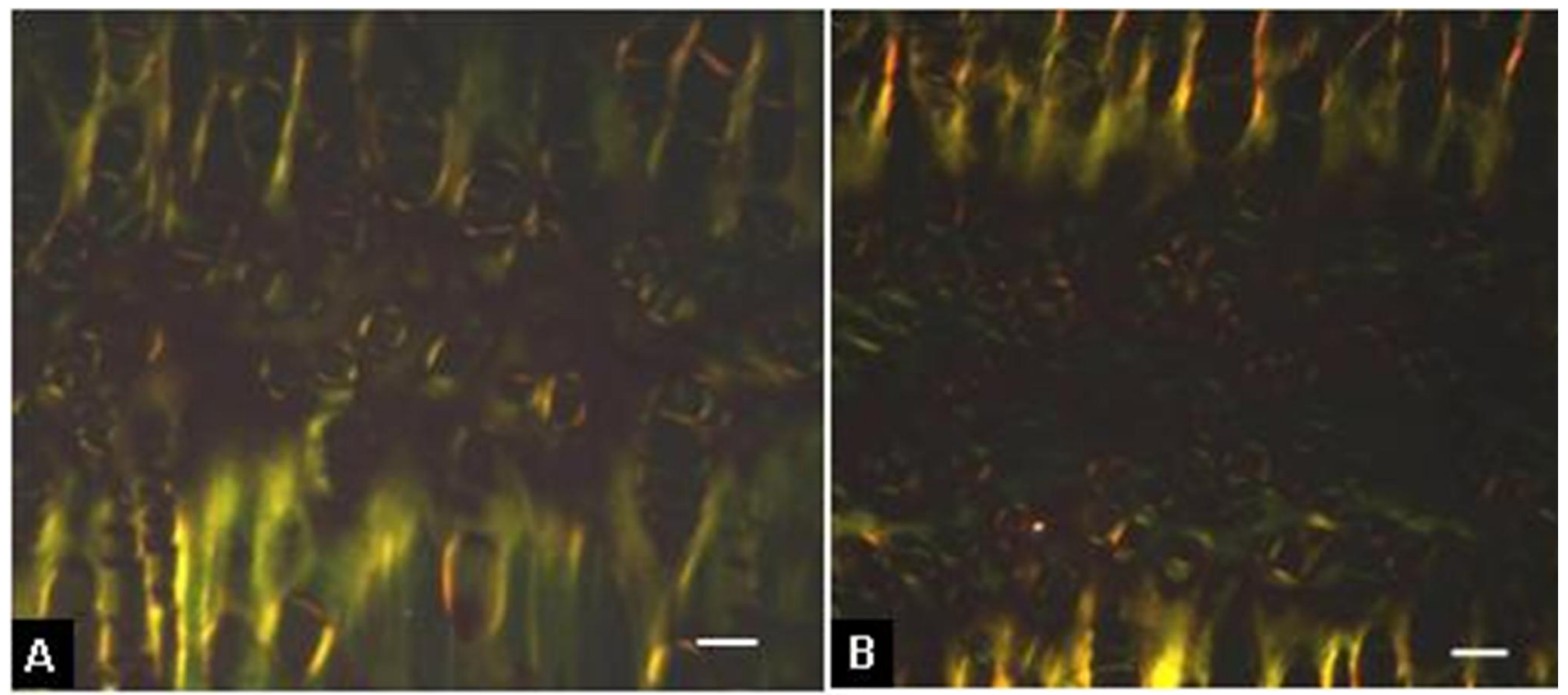

Notar, no grupo N, as fibras colágenas do tipo II (verde) ocupando toda a região da SB com poucos loci de condrócitos em seu interior. No grupo $\mathrm{S}$, essas fibras estão dispostas na periferia da SB que exibe, em seu interior, número elevado de loci de condrócitos. (Picro-sirius sob luz polarizada. Barra de calibração: $10 \mu \mathrm{m}$ ).

A MEC constituinte do PC dos animais do grupo $\mathrm{N}$ apresentou-se densa e uniformemente arranjada, com coloração intensa, contrastando com o aspecto difuso tanto na cor como na densidade da MEC do PC dos animais do grupo S.

$\mathrm{Na} \mathrm{SB}$, tanto no grupo $\mathrm{N}$ quanto no grupo $\mathrm{S}$ a MEC manteve o aspecto uniforme na sua distribuição bem como na homogeneidade da coloração (Figura 17). 
Figura 17 - Aspectos da MEC no PC e na SB dos grupos Nutrido $(A, C)$ e Subnutrido $(B, D)$, respectivamente.
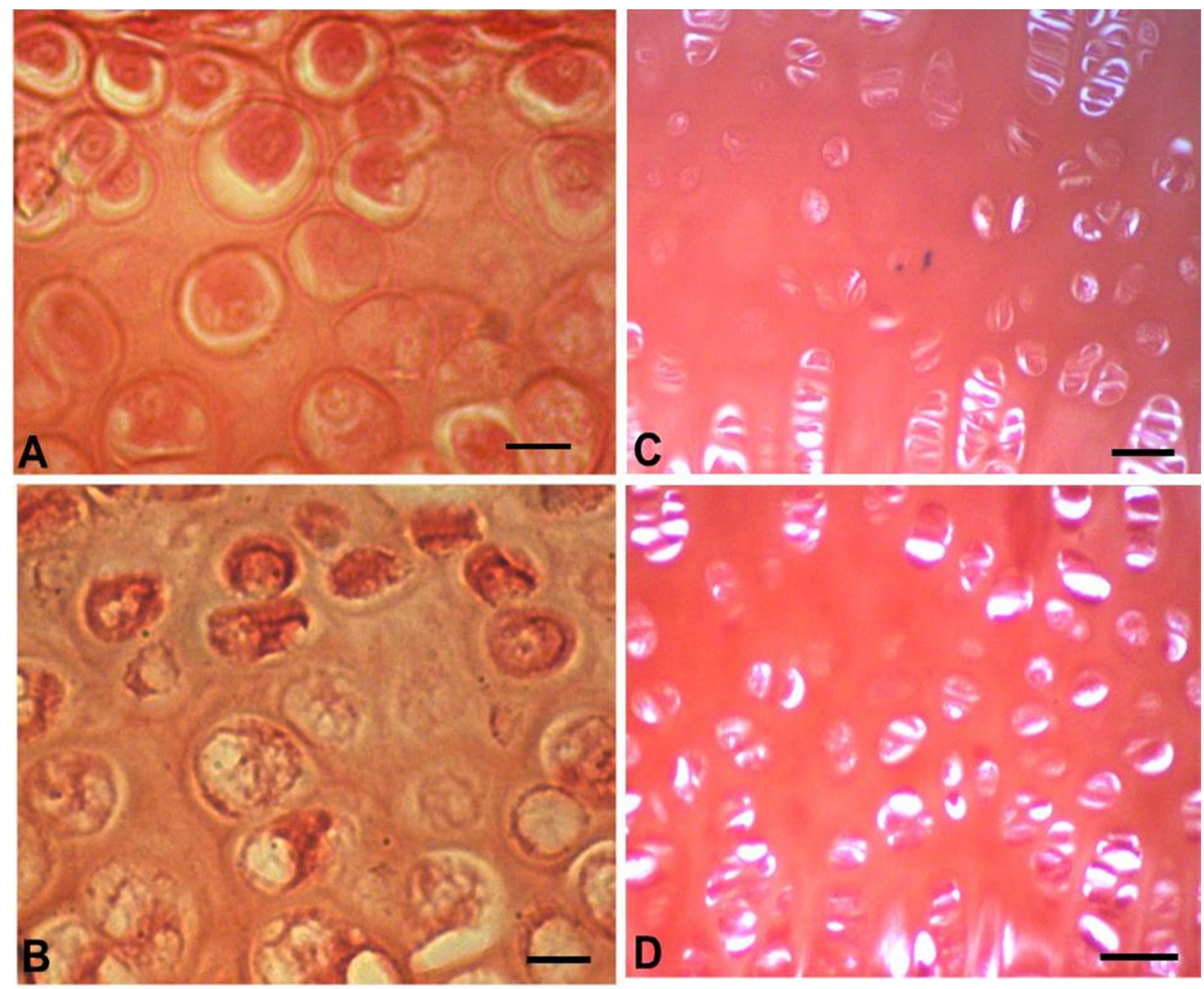

Comparar entre os grupos, as diferenças de distribuição e coloração da matriz. $\mathrm{Na} \mathrm{SB}$, não foram verificadas diferenças entre os grupos quanto a esses aspectos (C e D). (Safranina-O. Barra de calibração: A, B-10 $\mu \mathrm{m}$; C, D-25 $\mu \mathrm{m}$ ). 
5 DISCUSSÃO 
Alvo de diversos estudos, particularmente no campo da morfologia, a subnutrição é um processo que pode ser estabelecido experimentalmente de diversas maneiras, como a diminuição pura e simples da oferta de alimento (FIRMANSYAH et al., 1989); a elaboração de uma dieta hipoprotéica, a manipulação do tamanho da ninhada, separação materna temporal ou ligadura cirúrgica dos mamilos para prejudicar o aleitamento (HUBER et al., 2013), ou até mesmo conjugando-se os diferentes fatores (WINICK; NOBLE, 1966).

Os efeitos da subnutrição protéica alterando os níveis de caseína da dieta têm sido avaliados em diferentes componentes do aparelho estomatognático como 0 processo condilar da mandíbula (BOLDRINI, 2003), o nervo alveolar inferior (BINOTTI, 2003) a polpa dentária (GONÇALVES, 2012), e as mucosas lingual e palatina (LUIZ, 2012; VONO, 2012). Na presente pesquisa, optou-se por esse modelo de subnutrição, pelo fato da caseína conter aminoácidos essenciais indispensáveis ao organismo, e a sua supressão comprometer a estrutura de diversos órgãos e tecidos (DA SILVA, et al., 2013; OHISHI, et al., 2012).

De acordo com Rozzi et al. (2005) os estresses ambientais durante o desenvolvimento resultam em alterações transitórias do crescimento; cessada a ação, há o retorno imediato do desenvolvimento normal. A subnutrição protéica, que promove a interrupção de uma determinada "programação de crescimento préestabelecida" (FARNUM et al., 2003; PRADER et al., 1963;) e é descrita como responsável por uma mudança no ritmo e no tempo do crescimento do indivíduo (GOLDEN, 1994; PUCCIARELLI, 1987) desempenha, nas fases pré e pós-natal precoce, um papel fundamental no crescimento pós-natal, que altera a programação previamente determinada para o desenvolvimento de vários órgãos (BARKER, 2000; LUCAS, 1994, 1998;), até mesmo ao longo de várias gerações (MILLER; GERMAN, 1999; REICHLING; GERMAN, 2000). Com relação ao crescimento e ao desenvolvimento craniofacial, o baixo teor protéico parece afetar os componentes do neurocrânio e do viscerocrânio (DRESSINO; PUCCIARELLI, 1997) que, dada à diversidade de origem embriológica, exibem ritmos de crescimento diferentes. 
Desta forma, alguns aspectos relativos a presente pesquisa devem ser destacados. Inicialmente, muito embora sob o aspecto estatístico não se tenha observado uma diminuição na espessura das camadas do PC nos animais do grupo $S$, como confirmado por Cavalli (2011), também na cartilagem do PC de ratos subnutridos, o protocolo de subnutrição empregado mostrou-se eficiente, uma vez que foram observadas características estruturais que podem ser relacionadas a um processo de atraso no desenvolvimento, como o predomínio da densidade de fibras colágenas do tipo III no PC. Os dados também permitem inferir que o PC e a SB exibiram aspectos diversos frente ao processo de subnutrição, onde a aparente desorganização das camadas, bem como a coloração e densidade da MEC do PC dos animais do grupo S, não foi verificada na SB. Isto reforça a teoria da reação distinta de estruturas com origem embriológica e ritmos de crescimento diversos e concorda com Da Silva et al. (2013), ao afirmarem que a subnutrição intrauterina é capaz de determinar um retardo no crescimento dos órgãos em geral.

Ao curto prazo, a restrição protéica resulta também na diminuição da amplitude e na concentração de liberação de GH e de IGF-I no plasma, e na concentração de insulina, responsáveis pelo crescimento em geral (BOURRIN et al., 2000; ELKHATTABI et al., 2003; HAREL, TANNENBAUM, 1993; JIMENEZ-GANCEDO et al., 2004; THISSEN et al., 1994; UNDERWOOD et al., 1994).

No PC, a produção de IGF-I foi confirmada por técnicas de biologia molecular e imunohistoquimica (MAOR et al., 1993; VISNAPUU et al., 2002). Apesar do GH ter um importante papel no crescimento e no desenvolvimento craniofacial de humanos (PIRINEN, 1995), mais especificamente o IGF-I é um dos responsáveis pela síntese de matriz nas cartilagens primárias e secundárias (MAOR et al., 1993; VISNAPUU et al., 2001; XIAO-BING et al., 1998) uma condição confirmada em pesquisas de diferentes autores na localização IGF-IR nas camadas da cartilagem do PC.

Maor et al., (1993) detectaram esses receptores na camada pré-condroblástica do $P C$ de ratos neonatais, enquanto que, em ratos com 28 dias de vida, sua localização foi verificada na parte superior da camada condroblástica (FUENTES et al., 2002; LIVNE et al., 1997). Em estudos in vitro realizados por Oberbauer e Peng (1995) a maior 
reatividade do IGF-IR foi encontrada também na camada condroblástica dos discos de crescimento, o local onde ocorre a maior taxa mitótica no tecido.

O eixo IGF-I é marcadamente alterado em situações clínicas de subnutrição, incluindo anorexia nervosa, diabetes mellitus mal controlada, bem como na subnutrição experimentalmente induzida (MUNÕZ et al., 1996; UNDERWOOD et al., 1994), com as concentrações circulantes de IGF-I drasticamente reduzidas, mesmo quando a secreção de GH encontra-se aumentada ou inalterada (ARGENTE et al., 1997).

A importância dos dados obtidos no presente estudo reside especialmente no fato de se ter confirmado a correlação dos IGFs com as condições nutricionais nos diferentes grupos, evidenciando que a subnutrição influenciou tanto na regulação do peptídeo IGF-I, como na expressão dos receptores (IGF-IR). Segundo LeRoith et al. (1995) e MCDonald et al. (2007), o estado nutricional é o regulador mais importante da expressão dos receptores de IGF-I, estando o sistema de IGFs altamente sintonizado com a disponibilidade de nutrientes responsáveis pelo crescimento. A privação proteica (ou energética) afeta a transcrição de RNAm do peptídeo de IGF-I, resultando em redução dos seus níveis sanguíneos e locais. Como forma de neutralizar essa diminuição e manter os seus efeitos biológicos, é possível que ocorra um aumento da expressão do receptor, secundário à diminuição da concentração local de IGF-I, por um mecanismo fisiológico denominado "upregulation" (PAS; EVERTS; HAAGSMAN, 2004). Os dados aqui expostos indicam a ocorrência de diferenças estatisticamente significantes das expressões do IGF-I e de seu receptor entre os grupos $\mathrm{N}$ e $\mathrm{S}$, uma vez que os animais nutridos apresentaram alta expressão para ambos, conferindo assim o crescimento promovido pela presença desse fator, e demonstrando o seu comprometimento com a subnutrição, uma vez que a mesma foi capaz de modificar o padrão de expressão desse peptídeo e de seu receptor, tanto no PC quanto na SB. Diante disso, pode-se sugerir que, em termos quantitativos, os animais subnutridos tiveram os seus mecanismos de crescimento alterados pela depleção proteica.

Existem controvérsias a respeito dos efeitos da restrição de nutrientes sobre as concentrações de IGF-IR, em diferentes tecidos. Desta forma, Gonçalves (2012) demonstrou em ratos jovens subnutridos que, além do padrão morfológico da polpa dental ter sofrido alteração, a expressão diminuída do IGF-I e do IGF-IR também 
acarretou no retardo do crescimento do tecido pulpar. No córtex cerebral e no cerebelo de ratos jovens submetidos à subnutrição proteica pré-natal, Maheshwari et al. (1997) relataram um decréscimo de receptores de IGF-I; no entanto, a concentração das proteínas ligantes (IGFBPs) foi relativamente mais alta de IGFBP-2 e IGFBP-3, do que a encontrada para os receptores, cujo significado poderia ser a manutenção da atividade metabólica, enquanto há um retardo da proliferação e diferenciação celulares.

Como, na presente pesquisa, não foram realizadas técnicas para se quantificar as concentrações séricas das IGFBPs, não se pode afirmar que a restrição proteica, ao induzir a um decréscimo de IGF-I circulante nos animais do grupo $S$ devido a um mecanismo de "downregulation", determinou uma redução ainda maior na expressão dos seus receptores (GUYTON; HALL, 2006). A hipótese mais plausível é a que leva em consideração a complexidade de interação dos hormônios peptídicos com seus receptores de membrana celular. Assim, considerando que o IGF-I raramente está ausente no ambiente celular e sua dissociação dos receptores ocorre de forma lenta (ZHONG et al., 1993), é possível que nos grupos aqui avaliados, os receptores (IGFIRs) estivessem sempre ocupados pelos ligantes (peptídeos), dificultando a interpretação em separado dos dados referentes ao peptídeo e ao receptor, apenas pela técnica de imunohistoquímica. 
6 CONCLUSÕES 
No PC e na SB de ratos, com a metodologia empregada, e face aos resultados obtidos, relativamente ao estado de subnutrição, é lícito concluir-se que:

1. A espessura das camadas constituintes do PC e da SB não foram influenciadas;

2. Ocorreu uma diminuição da densidade de células imunorreativas ao IGF-I e ao IGF$\mathrm{IR}$;

3. Influenciou na composição da matriz cartilagínea;

4. Alterou a estruturação colágena;

Desta forma, pode-se admitir que a subnutrição, pelo menos na fase de vida dos animais aqui avaliados, não promoveu alterações compatíveis com degeneração do tecido cartilagíneo, mas um atraso no desenvolvimento das estruturas do PC e da SB. 
REFERÊNCIAS 


\section{REFERÊNCIAS}

ADAMS, P. H. Intra-uterine growth retardation in the pig. II. Development of the Skeleton, v. 19, p. 341-353, 1971.

ALIPPI, R. M.; BARCELO, A. C.; BARDI, M.; FRIEDMAN, S. M.; RIO, M. E.; BOZZINI, C. E. Effect of protein-free diet on growth of the skeletal units of the rat mandible. Acta Odontologica Latinoamericana, v. 1, p. 9-13, 1984.

ARGENTE, J.; CABALLO, N.; BARRIOS, V.; MUNÕZ, M. T.; POZO, J.; CHOWEN, J. A. Multiple endocrine abnormalities of the growth hormone and insulin-like growth factor axis in patients with anorexia nervosa: effect of short-and long-term recuperation. Journal of Clinical Endocrinology and Metabolism, v. 82, p. 2084-2092, 1997.

BAPTISTA, J. S. Repercussões morfológicas no timo de ratos jovens submetidos à desnutrição protéica e à renutrição precocemente corrigida. 2008. $107 \mathrm{f}$. Dissertação (Mestrado em Ciências Morfofuncionais) - Instituto de Ciências Biomédicas, Universidade de São Paulo, São Paulo, 2008.

BARKER, D. J. P. In utero programming of cardiovascular disease. Theriogenology, v. 53, p. 555-574, 2000.

BINOTTI, C. B. Repercussões morfológicas da desnutrição protéica pré e pósnatale e da renutrição pós-natal sobre o nervo alveolar inferior de ratos jovens. 2003. 94 f. Tese (Doutorado em Ciências Morfofuncionais) - Instituto de Ciências Biomédicas, Universidade de São Paulo, São Paulo, 2003.

BJORK, A.; HELM, S. Prediction of the age of maximum pubertal growth in body height. Angle Orthodontontics, v. 37, p. 134-143, 1967.

BJORK, A.; SKILLER, V. Postnatal growth and development of the maxillary complex. In: MCNAMARA JR., J. A. (Ed.). Factors affecting the growth of the midface. Michigan: University of Michigan, Center for Human Growth and Development, 1976. p. 61-101.

De acordo com:

ASSOCIAÇÃO BRASILEIRA DE NORMAS TECNICAS. NBR 6023: informação e documentação: referencias: elaboração. Rio de Janeiro, 2002. 
BOLDRINI, S. C. Efeitos da desnutrição protéica pré e pós-natal e da renutrição pós-natal sobre o crescimento craniofacial de ratos wistar: análise craniométrica, morfoquantitativa e ultra-estrutural. 2003. 68 f. Tese (Doutorado Em Ciências) Instituto de Ciências Biomédicas, Universidade De São Paulo, São Paulo, 2003.

BOURRIN, S.; AMMANN, P.; BONJOUR, J. P.; RIZZOLI, R. Dietary protein restriction lowers plasma insulin-like growth factor I (IGF-I), impairs cortical bone formation, and induces osteoblastic resistance to IGF-I in adult female rats. Endocrinology, v. 141, p. $3149-3155,2000$.

BRETON, C.; PECHOUX, C.; MOREL, G.; ZINGG, H. H. Oxytocin receptor messenger ribonucleic acid: characterization, regulation, and cellular localization in the rat pituitary gland. Endocrinology, v. 136, p. 2928-2936, 1995.

CARLSON, D. S.; MCNAMARA, J. A. JR.; JAUL, D. H. Histological analysis of the growth of the mandibular condyle in the Rhesus monkey (Macaca mulatta). American Journal Anatomy, v.151, p. 103-117, 1978.

CARLSON, D. S.; GRABER, L. A. W.; HOFFMAN, D. L. Experimental studies of growth and adaptation of TMJ. In: MCNAMARA, J. A. JR. (Ed.). Current advances in oral surgery. Michigan: University of Michigan, 1980. p. 28-77.

CAVALLI, M. A. Avaliação morfoquantitava dos efeitos da subnutrição e da renutrição protéica no processo condilar da mandíbula de ratos wistar: uma correlação com a expressão do receptor de insulin. 2011. 109 f. Dissertação (Mestrado em Ciências) - Faculdade de Veterinária e Zootecnia, Universidade de São Paulo, São Paulo, 2011.

CHEVERUD, J. M. Phenotypic, genetic, and environmental morphological integration in the cranium. Evolution, v. 36, p. 499-516, 1982.

CONSTANZO, L. S. Fisiologia. 2. ed. Rio de Janeiro (RJ): Guanabara Koogan, 2004. p. 308-330.

COPRAY, J. C.; LIEM, R. S. Ultrastructural changes associated with weaning in the mandibular condyle of the rat. Acta Anatomica, v. 134, p. 35-47, 1989.

COUPÉ, B.; GRIT, I.; DARMAUN, D.; PARNET P. The timing of "catch-up growth" affects metabolism and appetite regulation in male rats born with intrauterine growth restriction. American Journal of Physiology, v. 297, p. 813-824, 2009. 
DA SILVA, A. A.; BORBA, T. K.; DE ALMEIDA L., L.; CAVALCANTE, T. C.; DE FREITAS, M. F.; LEANDRO, C. G.; DO NASCIMENTO, E.; DE SOUZA, S. L. Perinatal undernutrition stimulates seeking food reward. International Journal of Development Neuroscience, v. 31, p. 334-341, 2013.

DELATTE, M.; VON DEN HOFF, J. W.; VAN RHEDEN, R. E. M.; KUIJPERSJAGTMAN, A. M. Primary and secondary cartilages of the neonatal rat: the femoral head and the mandibular condyle. European Journal Oral Science, v. 112, p. 156-162, 2004.

DE OLIVEIRA, B. C.; DE OLIVEIRA, F.; MARTINI, D. T.; PRISCO, C. R.; DA SILVA RIGUETTI, M. M.; LIBERTI, E. A.; DE CAMPOS BOLDRINI, S. The relative effects of severe burn injury and pre- and post-natal protein deprivation on mandibular condyle morphology. Histology and Histopathology, v. 25, p. 45-54, 2010.

DRESSINO, V.; PUCCIARELLI, H. M. Cranial Growth in Saimiri sciureus (Cebidae) and its alteration by nutritional factors: a longitudinal study. American Journal of Physical Anthropology, v. 102, p. 545-554, 1997.

EDOZIEN J. C.; SWITZER, B. R. Influence of diet on growth in the rat. Journal of Nutrition, v. 108, p. 282-290, 1978.

EL-KHATTABI, I.; GRÉGOIRE, F.; REMACLE, C.; REUSENS, B. Isocaloric maternal low-protein diet alters IGF-I, IGFBPs, and hepatocyte proliferation in the fetal rat. American Journal Physiology Endocrinology Metabolism, v. 285, p. 991-1000, 2003.

ENLOW, D. H. The human face: an account of the postnatal growth and development of the craniofacial skeleton. New York: Hoeber Medical Division, Harper and Row, 1968. p. 303.

ENLOW, D. H. Mandibular reactions during growth. In: MCNAMARA, J. A. JR. (Ed.). Determinants of mandibular form and growth. Michigan: University of Michigan, Centre of Human Growth and Development, 1975.

FARNUM, C. E.; LEE, A. O.; O'HARA, K.; WILSMAN, N. J. Effect of short-term fasting on bone elongation rates: an analysis of catch-up growth in young male rats. Pediatric Research, v. 53, p. 33-41, 2003.

FIELDS, H. W. Craniofacial growth from infancy through adulthood. Pediatric Clinics of North America, v. 38, p. 1053-1088, 1991. 
FIRMANSYAH, A.;SUWANDITO, L.; PENN, D.;LEBENTHAL, E. Biochemical and morphological changes in the digestive tract of rats after prenatal and postnatal malnutrition. The American Journal of Clinical Nutrition, v. 50, p. 261-268, 1989.

FUENTES, M. A.; OPPERMAN, L. A.; BELLINGER, L. L.; CARLSON, D. S.; HINTON, R. J. Regulation of cell proliferation in rat mandibular condylar cartilage in explant culture by insulin-like growth factor- 1 and fibroblast growth factor-2. Archives of oral biology, v. 47, p. 643-654, 2002.

FURSTMAN, L. L. Normal age changes in the rat mandibular joint. Journal of Dental Research, v. 45, p. 291-296, 1966.

GREEN, H.; MORIKAWA, M.; NIXON, T. A dual effector theory of growth-hormone action. Differentiation, v. 29, p. 195-198, 1985.

GOLDEN, M. H. N. Is complete catch-up possible for stunted malnourished children? European Journal of Clinical Nutrition, v. 48, p. 58-71, 1994.

GOLDRING, S. R.; GOLDRING, M. B. The role of cytokines in cartilage matrix degeneration in osteoarthritis. Clinical Orthopaedics and Related Research, v. 427, p. 27-36, 2004.

GONÇALVES, A. Avaliação morfoquantitativa das expressões do IGF-I, Insulina e de seus receptores na polpa dentária e no epitélio juncional de ratos wistar na fase púbere, submetidos à subnutrição proteica pré e pós-natal e à renutrição pós-natal. 2012. 91 f. Dissertação (Mestrado em Ciências) - Faculdade de Medicina Veterinária e Zootecnia, Universidade de São Paulo, São Paulo, 2012.

GUYTON, A. C.; HALL, J. E. Tratado de Fisiologia médica. 11. ed. Rio de Janeiro (RJ): Ed. Elsevier, 2006.

HALL, B. K. Bone. Florida: CRC Press Inc., 1994. v. 9, p. 1-61.

HAREL, Z.; TANNENBAUM, G. S. Dietary protein restriction impairs both spontaneous and growth hormone-releasing factor-stimulated growth hormone release in the rat. Endocrinology, v. 133, p. 1035-1043, 1993.

HERINGTON, A. C.; CORNELL, H. J.; KUFFER, A. D. Recent advances in the biochemistry and physiology of the insulin-like growth factor/somatomedin family. Int. The Journal of Biochemistry, v. 15, p. 1201-1210, 1983. 
HERRING, S. W. Formation of the vertebrate face: epigenetic and functional influences. American Zoologist, v. 33, p. 472-483, 1993.

HILL, J. D.; PETRIK, J.; ARANY, E. Growth factors and the regulation of fetal growth. Diabetes Care, v. 21, p. 60B-69B, 1998.

HUBER, R. C.; KOLB, A. F.; LILLICO, S.; CARLISLE, A.; SANDØE, P.; SØRENSEN, D.B.; REMUGE, L.; WHITELAW, B. C.; OLSSON, A. I. Behaviour of postnatally growthimpaired mice during malnutrition and after partial weight recovery. Nutritional Neuroscience, v. 16, p. 125-34. 2013.

ISAKSSON, O. G. P.; EDEN, S.; JANSSON, J. O. Mode of action of pituitary growth hormone on target cells. Annual Review of Physiology, v. 47, p. 483-499, 1985.

JIMÉNEZ-GANCEDO, B.; AGIS-TORRES, A.; LÓPEZ-OLIVA, M. E.; MUÑOZMARTÍNEZ, E. Dietary protein concentration correlates in a complex way with glucose metabolism and growth performance in pregnant rats. Endocrinology, v. 26, p. 277289, 2004.

JUNQUEIRA, L. C.; CARNEIRO, E. J. Histologia Básica. 35. ed. Rio de Janeiro: Ed. Guanabara, 1979.

KANTOMAA, T.; TUOMINEN, M.; PIRTTINIEMI, P.; RÖNNING, O. Weaning and the histology of the mandibular condyle in the rat. Acta Anatomica, v. 144, p. 311-315, 1992.

KILIARIDIS, S.; THILANDER, B.; KJELLBERG, H.; TOPOUZELIS, N.; ZAFIRIADIS, A. Effect of low masticatory function on condylar growth: a morphometric study in the rat. American Journal of Orthodontics and Dentofacial Orthopedics, v. 116, n. 2, p. 121-125, 1999.

LANSDOWN, A. B. Epidermal differentiation in normal and growth-retarded infants: studies in two animal models and human babies. British Journal of Dermatology, $v$. 99, p. 139-146, 1978.

LAZOWSKI, D. A.; FRAHER, L. J.; HODSMAN, A.; STERR, B.; MODROWSKI, D.; VAN, V. K. M. Regional variation of insulin-like growth factor-I gene expression in mature rat bone and cartilage. Bone, v. 15, p. 563-576, 1994. 
LEROITH, D.; WERNER, H.; BEITNER-JOHNSON, D.; ROBERTS, C. T. Molecular and cellular aspects of the insulin-like growth factor i receptor, Endocrine Reviews, v.16, p.143-163, 1995.

LIN, W. W.; OBERAUER, A. A. Spatiotemporal expression of alternatively spliced IGF-I mRNA in the rat costochondral growth plate. Journal of Endocrinology, v. 160, p. 461467, 1999.

LIVNE, E.; LAUFER, D.; BLUMENFELD, I. Osteoarthritis in the temporo-madibular joint (TMJ) of aged mice and in vitro effect of TGF- $\beta 1$ on cell proliferation, matrix synthesis and alkaline phosphatase activity. Microscopy Research and Technique, v. 37, p. 314-323, 1997.

LUCAS, A. Role of nutritional programming in determining adult morbidity. Archives of Disease in Childhood, v. 71, p. 288-290, 1994.

LUDER, H. U. Structure and growth activities of the mandibular condyle in monkeys (Macaca fascicularis): I. Intracondylar variations. American Journal of Anatomy, v. 166, p. 223-235, 1983.

LUIZ, L. F. Repercurssões morfológicas da subnutrição protéica pré e pós-natal e da renutrição pós-natal na mucosa lingual de ratos Wistar nas fases púbere e adulta: avaliações estrututral e da expressão do IGF-I e IGF-IR, da insulina e seu receptor. 2012. 92 f. Dissertação (Mestrado em Ciências) - Faculdade de Medicina Veterinária e Zootecnia - Universidade de São Paulo, São Paulo, 2012.

LUNA, L. G. Histologic staining methods of the Armed Forces. Institute of Pathology, 3. ed. 1968, p. 62.

MAHESHWARI, H. G.; MERMELSTEIN, S.; VONSCHLEGELL, A. S.; SHAMBAUGH, G. E 3rd. Alteration in IGF-I binding in the cerebral cortex and cerebellum of neonatal rats during protein-calorie malnutrition. Neurochemical Research, v. 22, n. 3, p. 313319, 1997.

MALCOLM, L. Protein-energy malnutrition and growth. In: Faulkner, F., Tanner, J. (Eds.) Human Growth. Plenum Press, New York, 1979.

MAOR, G.; LARON, Z.; ESHET, R. The early postnatal development of the murine mandibular condyle is regulated by endogenous insulin-like growth factor- I. Journal of Endocrinology, v. 137, p. 21-26, 1993. 
MCDONALD, T. J.; NIJLAND, M. J. NATHANIELSZ, P. W. The insulin-like growth factor system and the fetal brain: Effects of poor maternal nutrition. Reviews in Endocrine and Metabolic Disorders, v. 8, p. 71-84, 2007.

MCNEILL, C. Management of temporomandibular disorders: concepts and controversies. The Journal Prosthetic Dentistry, v. 77, p. 510-522, 1997.

MILLER, J.; GERMAN, R. Protein malnutrition affects the growth trajectories of the craniofacial skeleton in rats. Journal of Nutrition, v. 129, p. 2061-2069, 1999.

MOLTENI, A.; MODROWSKI, D.; HOTT, M.; MARIE, P. J. Alterations of matrix and cellassociated proteoglycans inhibit osteogenesis and growth response to fibroblast growth factor-2 in cultured rat mandibular condyle and calvaria. Cell and Tissue Research, v.295, p. 523-536, 1999.

MONTE, C. M. G. Desnutrição: um desafio secular à nutrição infantil. Journal of Pediatrics, v. 76, p. 285-297, 2000.

MORSE, A. Formic acid-sodium citrate decalcification and butyl alcohol dehydration of teeth and bones for sectoring in paraffin. Journal of Dental Research, v. 24, p. 143153, 1945.

MUNÕZ, M. T.; BARRIOS, V.; POZO, J.; ARGENTE, J. Insulin-like growth factor I, its binding proteins 1 and 3 , and growth hormonebinding protein in children and adolescents with insulindependent diabetes mellitus: clinical implications. Pediatric Research, v. 39, p. 992-998, 1996.

MOYERS, R. E. Ortodontia. 4. ed. Rio de Janeiro (RJ): Guanabara Koogan., 1991. p. 44-63.

NAEYE, R. L. Cardiovascular abnorlaities in infants malnourished beforebirth. Biology of the Neonate, v. 8, p. 104-113, 1965.

NAKAMOTO, T.; PORTER, J. R.; WINKLER, M. M. The effect of prenatal protein-energy malnutrition on the development of mandibles and long bones in newborn rats. Brit. Journal of Nutrition, v. 50, p. 75-80, 1983.

NEWMAN, J. J.; STROME, D. R.; GOODWIN, C. W.; MASON, A. D.; PRUITT, B. A. Altered muscle metabolism in rats after thermal injury. Metabolism, v. 31, p. 1229-1233, 1982. 
NILSSON, A.; LINDAHL, A.; EDEN, S.; ISAKSSON, O. G. P.; RYMO, L. Regulation by $\mathrm{GH}$ of insulin-like growth factor-I mRNA expression in rat epiphyseal growth plate as studied with in situ hybridization. Journal of Endocrinology, v. 125, p. 67-74. 1990.

OBERBAUER, A. M.; PENG, R. Fractionation of growth plate chondrocytes: differential expression of igf-i and growth hormone and IGF-I receptor m-rna in purified populations. Connect Tissue Research, v. 31, p. 179-187, 1995.

OHISHI, T.; WANG, L.; AKANE, H.; SHIRAKI, A.; SATO, A.; UEMATSU, M.; SUZUKI, K.; MITSUMORI, K.; SHIBUTANI, M. Adolescent hyperactivity of offspring after maternal protein restriction during the second half of gestation and lactation periods in rats. The Journal of Toxicological Science, v. 37, p. 345-52, 2012.

OHLSSON, C.; SJÖGREN, K.; JANSSON, O. G. P. The relative importance of endocrine versus autocrine/paracrine insulin-like growth factor-I in the regulation of body growth. Pediatric Nephrology, v.14, p. 541-543, 2000.

ONLEY, R. C.; MOUGEY, E. B. Expression of the components of the insulin-like growth factor axis across the growth plate. Molecular and Cellular Endocrinology, v. 156, p. 63-71, 1999.

PAS, M. F. W.; HAAGSMAN, H. P.; EVERTS, M. E. Muscle development of livestock animals: physiology, genetics and meat quality. Wallingford: CABI Publishing, 2004. p. 432.

PRADER, A.; TANNER, J. M.; VON HARNAK, G. A. Catchup growth following illness or starvation. Journal of Pediatric, v. 62, p. 646 - 659, 1963.

PIMSTONE, B. L.; BARBEZAT, G.; HANSEN, J. D., MURRAY P. Studies on growth hormone secretion in protein-calorie malnutrition. The American Journal of Clinical Nutrition, v. 21, p. 482-487, 1968.

PIRINEN, S. Endocrine regulation of craniofacial growth. Acta Odontologica Scandinava, v. 53, p.179-85, 1995.

PIRTTINIEMI, P.; KANTOMAA, T.; SALO, L.; TUOMINEN, M. Effect of redeced articular function on deposition of type I and type II colagens in the mandibular condylar cartilage of the rat. Archives of Oral Biology, v. 141, p. 127-131, 1996.

PUCCIARELLI, H. M. Craniofacial development of the rat with respect to vestibular orientation. Acta Anatomy, v. 100, p. 101-110, 1978. 
PUCCIARELLI, H. M. Effects of race, sex, and nutrition on craniofacial differentiation in rats. A multivariative analys. American Journal of Physical Anthropology, v. 53, p. 359-368, 1980.

PUCCIARELLI, H. M. Growth of the functional components of the rat skull and its alterations by nutritional effects. American Journal of Physical Anthropology, v. 56, p. 33-41, 1981.

PUCCIARELLI, H. M.; OYHENART, E.E. Effects of maternal food restriction during lactation on craniofacial growth in weanling rats. American Journal of Physical Anthropology, v. 72, p. 67-75, 1987.

REEVES, P.G.; NIELSEN, F.H.; FAHEY JR,G. C. AIN-93 purified diets for laboratory rodents: final report of the American Institute of Nutrition ad hoc writing committee on the reformulation of the AIN-76A rodent diet. Journal of Nutrition, v. 123, p. 1939-1931, 1993.

REICHLING, T.; GERMAN, R. Bones, muscles and organs of protein malnourished rats (Ratus norvegicus) grow more slowly but for longer durations to reach normal final size. Journal of Nutrition, v. 130, p. 2326-2332, 2000.

ROMEIS, B. Mikroskopische Technick. 6. ed. Oldenbourg: München, 1968.

RÖNNING, O. Basicranial synchondroses and the mandibular condyle in craniofacial growth. Acta Odontologica Scandinavica, v.53, p. 162-166, 1995.

ROZZI, F. V. R.; GONZÁLEZ-JOSÉ, R.; PUCCIARELLI, H. M. Cranial growth in normal and low-protein-fed Saimiri. An environmental heterochrony. Journal of Human Evolution, v, 49, p. 515-535, 2005.

SCHUMACHER, G. H. Regulative and adaptative factors in craniofacial growth. Annals of Anatomy, v. 181, p. 9-13, 1999.

SHRADER, R. E.; ZEMAN, F. J. Effect of maternal protein deprivation on morphological and enzymatic development of neonatal rat tissue. Journal of Nutrition, v. 99, p. 401-412, 1969.

SILVERTHORN, A. C.; OBER, W.C.; GARRISON, C.W. Fisiologia Humana: Uma Abordagem Integrada, 2. Ed., São Paulo, Manole, 2003. p. 672-674. 
SJÖGREN, K.; LIU, J. L.; BLAD, K.; SKRTIC, S.; VIDAL, O.; WALLENIUS, V.; LEROITH, D.; TÖRNELL, J.; ISAKSSON, O. G. P.; JANSSON, J. O.; OHLSSON, K. Liver derived insulin-like growth factor I(IGF-I) is the principal source of IGF-I in blood but is not required for postnatal body growth in mice. Proceeding of the National Academy of Sciences, v. 96, p. 7088-7092, 1999.

STEFANINI, M.; DE MARTINO, C.; LUCIANO, Z. Fixation of ejaculated spermatozoa dor electron microscopy. Nature, v. 126, p. 173-174, 1967.

TAJIMA, Y.; KAWASAKI, M.; KURIHARA, K.; UEHA, T.; YOKOSE, S. Immunohistochemical profile of basic fibroblast growth factor and heparin sulphate in adult rat mandibular condylar cartilage. Archives of Oral Biology, v. 43, p. 873-877, 1998.

TEN CATE, R. Oral Histology. 5 ed. Mosby-Year Book, Inc. cap. 3, 1998.

TERAMOTO, M.; KANEKO, S.; SHIBATA, S.; YANAGISHITA, M.; SOMA, K. Effect of compressive forces on extracelular matrix in rat mandibular condylar cartilage. J. Bone Mineral Metabolism, v. 21, p. 276-286, 2003.

THILANDER, B.; CARLSSON, G. E.; INGERVALL, B.Postnatal development of the human temporomandibular joint. I. A histological study. Acta Odontologica Scandinavica, v.34, p.34, p. 117-126, 1976.

THISSEN, J. P.; KETESLEGERS, J. M.; UNDERWOOD, L. E. Nutritional regulation of the insulin-like growth factors. Endocrine Reviews, v. 15, p. 80-101, 1994.

ULRICH, A.; GRAY, A.; TAM, A. W.; YANG-FENG, T.; TSUBOKAWA, M.; COLLINS, C.; HENZEL, W.; LE BON, T.; KATHURIA, S.; CHEN, E.; JACOBS, S.; FRANCKE, U.; RAMACHANDRAN, J.; FUJITA, Y. Y. Insulin-like growth factor I receptor primary structure: comparison with insulin receptor suggests structural determinants that define functional specificity. The Embo Journal, v. 5, p. 2503-2512, 1986.

UNDERWOOD, L. E.; THISSEN, J. P.; LEMOZY, S.; KETELSLEGERS, J. M.; CLEMMONS, D. R. Hormonal and nutrition regulation of IGF-I and its binding proteins. Hormone Research, v. 42, p. 145-151, 1994.

VAN ERUM, R.; MULIER, M.; CARELS, C.; VERBEKE, G.; ZEGHER, F. Craniofacial growth in short children born small for gestational age: effect of growth hormone treatment. Journal of Dental Research, v. 76, p. 1579-1586, 1997. 
VINKKA, H. Secondary cartilages in the facial skeleton of the rat. Proceedings of the Finnish Dental Society, v. 78, p. 131-137, 1982.

VISNAPPU, V.; PELTOMÄKI, T.; RÖNNING, O.; VAHLBERG, T.; HELENIUS, H. Growth hormone and insulin-like growth factor-I receptors in the mandibular joint of the rat. Journal of Dental Research, v. 80, p. 1903-1907, 2001.

VISNAPUU, V.; PELTOMÄKI, T.; RÖNNING, O.; SYRJANEN, S. Distribuition of insulinlike growth factor-I mRNA in the mandibular condyle and rib cartilage of the rat during growth. Archives of Oral Biology, v. 47, p. 791-798, 2002.

VONO, D. O. Repercussões morfológicas dos efeitso da subnutrição portéica pré e pós-natal e da renutrição pós-natal sobre a mucosa palatina de ratos Wistar na fase púbere: avaliações morfométricas e da expressão do IGF-I e IGF-IR e da insulina e seu receptor. 2012. Dissertação (Mestrado em Ciências) - Faculdade de Medicina Veterinária e Zootecnia, Universidade de São Paulo, São Paulo, 2012.

WORLD HEALTH ORGANIZATION. Informal Consultation on Community-Based management of Severe Malnutrition in Children. Geneva, 21-23 November 2005.

WINICK, M.; NOBLE, A. Cellular response in rats during malnutrition at various ages. The Journal of Nutrition, v. 89, p. 300-306, 1966.

WRIGHT, D. M.; MOFFETT, B. C. JR. The postnatal development of the human temporomandibular joint. American Journal of Anatomy, v. 141, p. 235-49, 1974.

YAMANO, T.; SHIMADA, M.; YAMASAKI, S.; GOTO, M.; OHOYA, N. Effect of maternal protein malnutrition on the developing cerebral cortex of mouse embryo: in electron microscopic study. Experimental Neurology, v. 68, p. 228-239, 1980.

YOUNG, R. W. The influences of cranial contents on postnatal growth on the skull in the rat. American Journal of Anatomy, v. 105, p. 383-409, 1959.

ZHONG, P.; CARA, J. F.; TAGER, H. S. Importance of receptor occupancy, concentration differences, and ligand exchange in the insulin-like growth factor I receptor system. Proceedings of the National Academy of Sciences of the United States of America, v. 90, n. 24, p. 11451-11455, 1993. 
ZHOU, J.; LU, Y.; GAO.; CHEN, Y. C.; LU, J. J.; BAI, Y. X.; SHEN, Y.; WANG, B. K. The growth hormone receptor gene is associated with mandibular height in a Chinese population. Journal of dental Research, v. 84, n. 11, p. 1052-1056, 2005.

XIAO-BING, L. I.; ZHOU, Z.; LUO, S. J. Expressions of IGF-1 and TGF-1 in the condylar cartilages of rapidly growing rats. The Chinese of Journal Dental Research, v. 2, p. 52-56, 1998. 